\title{
LEAN FLAMMABILITY LIMIT AS A FUNDAMENTAL REFRIGERANT PROPERTY Phase II
}

\author{
Interim Technical Report \\ 1 April 1995 - 30 March 1996 \\ Carole Womeldorf and William Grosshandler \\ BUILDING AND FIRE RESEARCH LABORATORY \\ National Institute of Standards and Technology \\ Gaithersburg, MD
}

30 April 1996

Prepared for
The Air-Conditioning and Refrigeration Technology Institute

Under

ARTI MCLR Project Number DE-FG02-91CE23810

This program is supported, in part, by U.S. Department of Energy (Office of Building Technology) grant number DE-FG02-91CE23810: Materials Compatibility and Lubricants Research (MCLR) on CFC-Refrigerant Substitutes. Federal funding supporting this program constitutes 93.57 \% of allowable costs. Funding from non-government sources supporting this program consists of direct cost sharing of $6.43 \%$ of allowable costs, and significant in-kind contributions from the air-conditioning and refrigeration industry. 


\section{DISCLAMMER}

Portions of this document may be illegible in electronic image products. Images are produced from the best available original document. 


\section{DISCLAIMER}

The U.S. Department of Energy's and the air-conditioning industry's support for the Materials Compatibility and Lubricants Research (MCLR) program does not constitute an endorsement by the U.S. Department of Energy, nor by the air-conditioning and refrigeration industry, of the views expressed herein.

\section{NOTICE}

This report was prepared on account of work sponsored by the United States Government. Neither the United States Government, nor the Department of Energy, nor the Air-Conditioning and Refrigeration Technology Institute, nor any of their employees, nor any of their contractors, subcontractors, or their employees, makes any warranty, expressed or implied, or assumes any legal liability or responsibility for the accuracy, completeness, or usefulness of any information, apparatus, product or process disclosed or represents that its use would not infringe privately-owned rights. 


\begin{abstract}
The flammability of alternative, non-ozone depleting refrigerants is an issue of growing importance to the air-conditioning and refrigeration industry. Test methods developed decades ago are being stretched to their limits when measuring the combustion behavior of weakly flammable refrigerants. This work is Phase II of a three part project to determine the feasibility, accuracy, and applicability of a premixed opposed-flow burner as an alternative means of measuring lean flammability limits.

In this work, the Phase II burner demonstrates the precision available to the opposed-flow technique for evaluating the lean flammability limit of weak fuels. Using opposed, converging nozzles, two jets support a premixed twin flame at different global strain rates and permit evaluation of the corresponding fuel concentration at the extinction point. Comparisons with published data support that the $\mathrm{LFL}_{0}$, a lean flammability limit value defined by the extrapolation of the extinction conditions to zero global strain, yields a consistent value. Using a computer simulation to analyze the uncertainty, the lean flammability limit of R-32 $\left(\mathrm{CH}_{2} \mathrm{~F}_{2}\right)$ in dry air is found to be $14.0 \% \pm 0.8 \%$ by volume; with a $43 \%$ relative humidity in air the $\mathrm{LFL}_{\mathrm{o}}$ of $\mathrm{R}-32$ is $14.1 \% \pm 0.6 \%$ by volume. Tests with $\mathrm{R}-134 \mathrm{a}\left(\mathrm{C}_{2} \mathrm{H}_{2} \mathrm{~F}_{4}\right)$ demonstrated that no flame could be sustained for ambient test conditions in dry air without adding a significant amount ( $2 \%$ by volume) of methane $\left(\mathrm{CH}_{4}\right)$ to the mixture.

Concurrent computational modeling of the combustion of R-32 in air, individually and in mixtures with $\mathrm{CH}_{4}, \mathrm{R}-125\left(\mathrm{C}_{2} \mathrm{HF}_{5}\right)$, and $\mathrm{R}-134 \mathrm{a}$, has been performed with the chemical kinetics code CHEMKIN. Estimates of the impact of the initial conditions (equivalence ratio, fuel composition, temperature, and relative humidity) on the magnitude of the laminar flame speed of a zero strain flame are made. This knowledge has been used to help interpret the counter-flow flame experiments and to predict the influence of other parameters that have not yet been investigated.
\end{abstract}




\section{Table of Contents}

\section{Introduction}

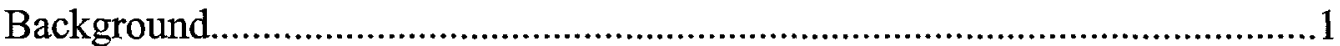

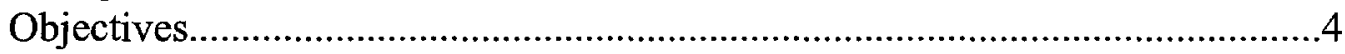

Experimental Facility

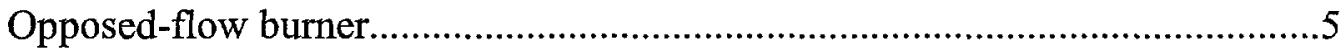

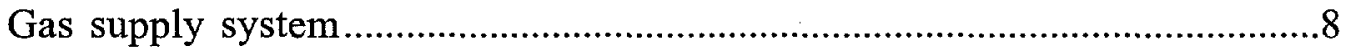

Flow control, data acquisition, and flow controller calibration..........................10

Experimental Results and Discussion

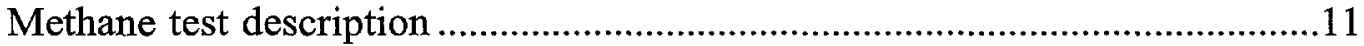

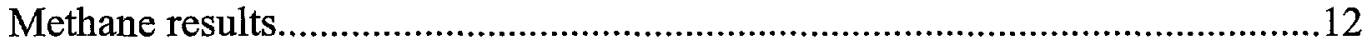

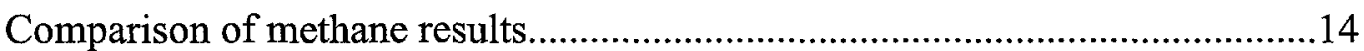

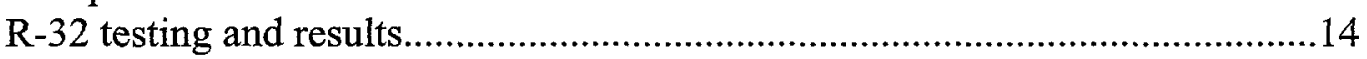

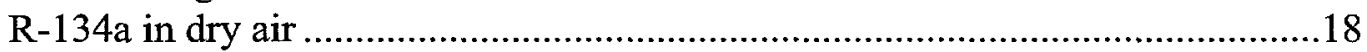

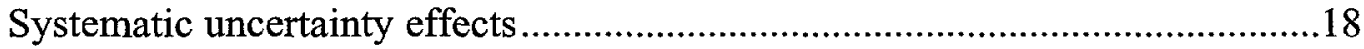

Theoretical Flame Calculations

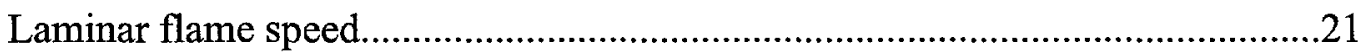

Chemical kinetics mechanism ..................................................................21

Numerical premixed flame model .........................................................22

Structure of the methane $\left(\mathrm{CH}_{4}\right)$ /air and R-32 $\left(\mathrm{CH}_{2} \mathrm{~F}_{2}\right)$ /air flames .....................24

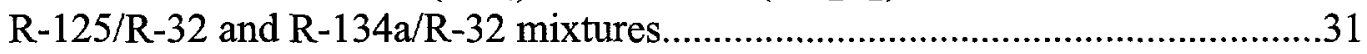

Impact of relative humidity and initial temperature..........................................33

Comparison between experimental opposed-flow and theoretical

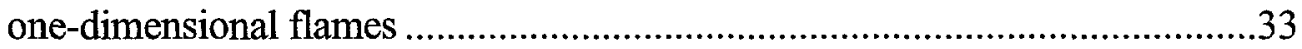

\section{Conclusions}

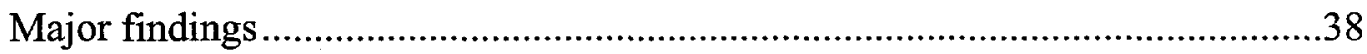

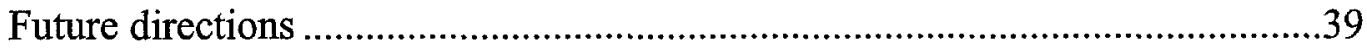

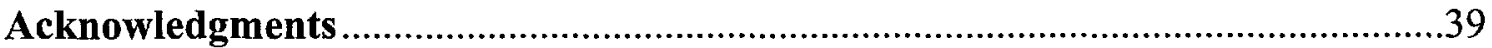

Appendix

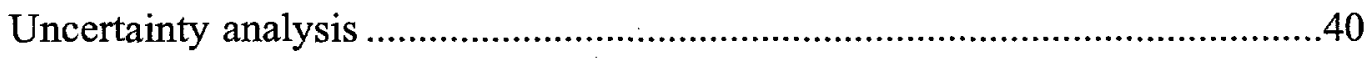

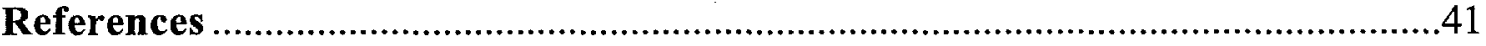




\section{Introduction}

Background: The banning of CFCs (chlorofluorocarbons) and some HCFCs (hydrochlorofluorocarbons) due to their ozone depletion potential has forced the air-conditioning and refrigeration industry to search for alternatives to efficient, non-flammable refrigerants. Early refrigerants were selected because they provided the optimum results for the given operational parameters of the time: efficiency, non-flammability, and cost; refrigerants that were flammable or less efficient were excluded. With ozone depletion potential and global warming as new parameters, refrigerants that were once considered less than ideal are being re-examined. As a consequence, it is now much more important to accurately measure the subtle flammability differences among many weakly flammable alternatives. Clearly identifying the hazard associated with pure alternative refrigerants, as well as optimizing mixtures of more efficient, flammable and less efficient, non-flammable refrigerants will mean safer and more cost effective options for the industry.

This project presents the first time that an opposed-flow burner has been used to determine the lean flammability of HFCs. Based on the work presented here, in Phase I (Womeldorf et al., 1995), and historically, the opposed-flow burner incorporates many elements which make it an ideal way to measure the fundamental lean flammability limits of alternative refrigerants. Table I summarizes advantages of the opposed-flow test facility.

A opposed-flow burner provides a clearly defined, theoretically reasoned lean flammability limit. The theory relies upon two facts: the twin flame created is nearly adiabatic and flame strain is controlled and quantified. With this technique it is possible to isolate and quantify the strain condition of the flame and by extrapolation, define a fundamental lean flammability limit which is independent of the flame strain and the burner.

In this burner a controlled, repeatable flame strain for a known fuel, oxidizer, and stoichiometry is established and the corresponding extinction condition is measured. Specifically, two small

Table I: $\quad$ Advantages of opposed-flow test facility and technique
Test Condition
Advantage

Zero strain rate extrapolation

Theoretically defensible definition of true flammability limit: zero strain.

Planar, near one-dimensional

Computer models exist for analysis and prediction (e.g., Tanoff et al., 1996)

Quantifiable strain condition

Premixed

Optimized burning condition (prerequisite for weak fuels near their limits)

Opposed jets with twin flames

Symmetry minimizes conductive and convective losses

Extinction condition

Unambiguous

Ignition-source independent

Flowing

Continuous test conditions 
flames are established on each side of a stagnation layer formed by two opposed jets of premixed fuel and air. The distance from the stagnation plane is a function of the flame speed of the mixture and the jet velocities. If the mixture is robust, (i.e. high flame speed), the flames are able to stabilize further from the low velocity region of the stagnation plane. Once the flames are stabilized, just above and below the stagnation plane, a lean extinction point is obtained by either increasing the global strain or reducing the fuel/air ratio, independently.

While the exact strain radially across the twin flame is difficult to measure, if the flow is approximated as inviscid and incompressible, the velocity gradient into the flame is proportional to the radial velocity gradient (Landau and Lifshitz, 1986) which is a radial strain measurement. Previous measurements with opposed-flow burners have defined a global strain rate, $K$, by the velocity gradient in the axial direction :

$$
K \equiv\left|\frac{d V_{z}}{d z}\right|=V_{z} / \frac{H}{2}
$$

where $V_{z}$ is the jet exit velocity and $H$ is the nozzle separation. The higher the velocity or the closer together the burner exits, the greater the strain on the twin flame. The velocity is determined by half the volumetric flow of the fuel/air mixture divided by the burner exit area. $K$ and the equivalence ratio $\Phi$, together describe the flame condition. $\Phi$ is defined generally by:

$$
\Phi \equiv \gamma \frac{\dot{\mathrm{X}}_{f}}{\dot{\mathrm{X}}_{a}}
$$

where $\dot{\mathrm{X}}_{f}$ is the molar flow of fuel, $\dot{\mathrm{X}}_{a}$ is the molar flow of air, and $\gamma$ is the molar flow of air divided by the molar flow of fuel for a stoichiometric mixture $\left(9.52\right.$ for $\mathrm{CH}_{4}, 4.76$ for $\mathrm{R}-32,7.14$ for R-134a). When $\Phi$ is less than one, the fuel/air mixture is described as "lean."

The refrigerant of primary interest in the current study is the hydrofluorocarbon $\mathrm{CH}_{2} \mathrm{~F}_{2}(\mathrm{R}-32)$. The flame structure of a simple hydrocarbon analog, methane $\left(\mathrm{CH}_{4}\right)$, has been studied over the past decades and is useful as a starting point for examining the composition of $\mathrm{CH}_{2} \mathrm{~F}_{2}$ /air flames. The complete reaction of a stoichiometric mixture of $\mathrm{CH}_{4}$ with air can be written as

$$
\mathrm{CH}_{4}+2\left(\mathrm{O}_{2}+3.76 \mathrm{~N}_{2}\right)=2 \mathrm{H}_{2} \mathrm{O}+\mathrm{CO}_{2}+3.76 \mathrm{~N}_{2}
$$

At final equilibrium the actual chemical composition includes a large number of secondary species. These, and the final temperature, were calculated from a thermodynamic description of the system using the NASA equilibrium code (Gordon and McBride, 1994) for a range of fuel/air equivalence ratios. The upper plot in Figure 1 shows the results for $\mathrm{CH}_{4}$. The lower plot shows a comparable calculation for $\mathrm{CH}_{2} \mathrm{~F}_{2}$ /air. For $\mathrm{CH}_{2} \mathrm{~F}_{2}$ the complete reaction of the stoichiometric mixture is written as

$$
\mathrm{CH}_{2} \mathrm{~F}_{2}+\left(\mathrm{O}_{2}+3.76 \mathrm{~N}_{2}\right)=2 \mathrm{HF}+\mathrm{CO}_{2}+3.76 \mathrm{~N}_{2}
$$




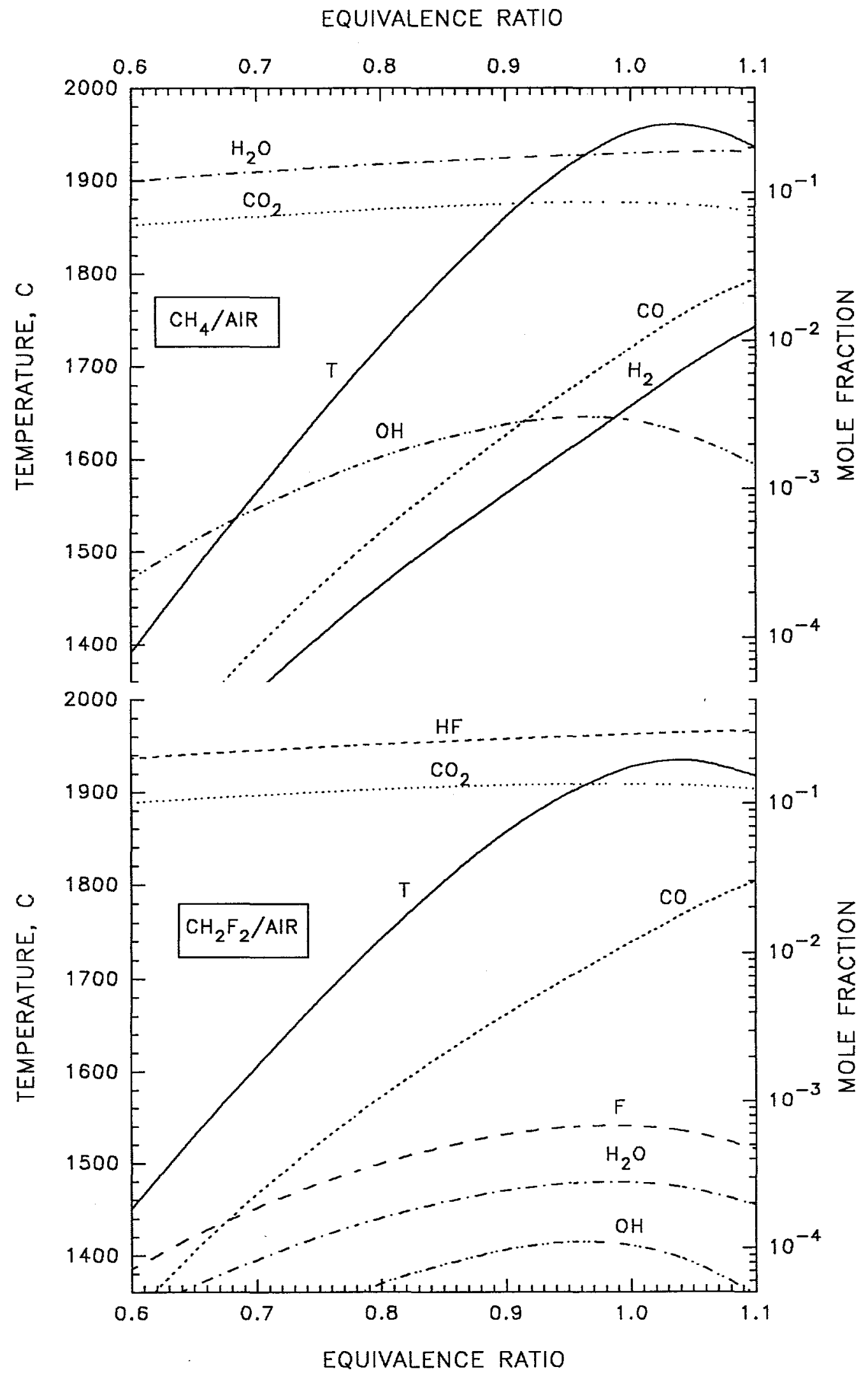

Figure 1: $\quad$ Adiabatic equilibrium composition and temperature for mixtures of $\mathrm{CH}_{4}$ (methane)/air and $\mathrm{CH}_{2} \mathrm{~F}_{2}(\mathrm{R}-32) /$ air. 
The equivalence ratio can be converted to volume percent fuel in the fuel/air mixture by using the relation:

$$
\% \text { Fuel }=100\left(\frac{\Phi}{\Phi+\gamma}\right)
$$

where $\gamma$ is defined as above. The equilibrium composition and temperature for a pure $\mathrm{CH}_{2} \mathrm{~F}_{2}$ /air mixture as a function of equivalence ratio was presented in the Phase I interim technical report (Womeldorf et al., 1995) neglecting species whose mole fraction was below $1 \times 10^{-6}$. In Figure 1, the calculations have been redone with the limit dropped to $1 \times 10^{-9}$.

These equilibrium calculations demonstrate that both fuel/air mixtures have the highest equilibrium temperature at about $1950{ }^{\circ} \mathrm{C}$, near $\Phi=1.04$. The primary products of a $\mathrm{CH}_{4} /$ air flame are $\mathrm{H}_{2} \mathrm{O}$ and $\mathrm{CO}_{2}$. The toxic gas $\mathrm{HF}$ is produced in large amounts from a $\mathrm{CH}_{2} \mathrm{~F}_{2} /$ air mixture. An equilibrium calculation describes only the end result of an infinite, isobaric, adiabatic reaction. It is the transition between the reactants and the end products which demonstrates the important distinctions in flame structure between $\mathrm{CH}_{2} \mathrm{~F}_{2}$ and $\mathrm{CH}_{4}$. The chemical kinetics of these two mixtures are discussed in the section on the theoretical flame calculations.

Objectives: Phase II of the Lean Flammability Limit project focuses on four key elements:

- The design, construction, and integration of a new opposed-flow test facility.

- Testing of the new facility by determining the lean flammability limit of $\mathrm{CH}_{4}$ in dry air.

- Determination of the lean flammability limit of R-32 in dry and humid air, and R-134a in dry air.

- Evaluation of the chemical kinetics mechanism for lean combustion of hydrofluorocarbons with one and two carbon atoms.

The new test facility incorporates significant improvements to the opposed-flow burner, the gas supply system, flow calibration and control, and the operating and data acquisition procedures over the work presented in Phase I. The capability to humidify the air has been added, providing the opportunity to assess the impact of water vapor on the $\mathrm{LFL}_{\mathrm{O}}$.

The opposed-flow burner improvements mentioned above are described in detail in the experimental facility section which follows. The experimental results and discussion section describes an extinction point test, the $\mathrm{CH}_{4}$ results, the R-32 testing and results (in dry and humid air), the R-134a testing and results, and a discussion of potential sources of systematic error observed during the testing. Theoretical flame calculations are then described, including computational modeling of $\mathrm{CH}_{4}$ and R-32/air mixtures alone and in combinations with each other and other refrigerants, including R-134a. This is followed by the conclusions of both the theoretical and experimental work and a brief discussion of future directions. 


\section{Experimental Facility}

The experimental facility consists of three major components: an opposed-flow burner, a gas supply system, and a flow control/data acquisition system. A systems diagram showing the interrelationship of these components is shown in Figure 2. Below they are discussed, along with the calibration of the mass flow controllers.

Opposed-flow burner: A cutaway view of the burner assembly is shown in Figure 3. The burner is located inside a $1 \mathrm{~m}^{3}$ chemical fume hood to safely vent the refrigerant and products of combustion. The shape of the burner is approximately cylindrical, about $100 \mathrm{~mm}$ in diameter and $450 \mathrm{~mm}$ high. It rests on a $12 \mathrm{~mm}$ thick aluminum base plate $300 \mathrm{~mm}$ in diameter. To eliminate unwanted air currents around the flame and direct the exhaust gases upward, the entire burner is enclosed within a $6 \mathrm{~mm}$ thick, $300 \mathrm{~mm}$ inside diameter plexiglas tube. There are upper and lower sections to the burner, both of which are identical in design and made of 304 stainless steel. The flames are located horizontally, midway between the sections.

Air premixed with the fuel enters the upper and lower sections through $9.5 \mathrm{~mm}$ tubes. The flow is uniformly distributed and straightened with an $80 \mathrm{~mm}$ inner diameter by $100 \mathrm{~mm}$ long tube containing a $35 \mathrm{~mm}$ long piece of $4 \mathrm{~mm}$ cell size honeycomb and fine mesh screens to break up large eddies. A converging nozzle with a cubical contour, following the design criteria of Morel (1975), reduces the area by a factor of over 40:1. The purpose of the straight section and contraction is to minimize the boundary layer and to produce a uniform velocity profile with low turbulence intensity at the exit. Nitrogen flows in a $1.0 \mathrm{~mm}$ thick concentric annulus to lift off the flame from the burner nozzle rim, to reduce the shear at the outer edge of the fuel/air jet and to quench the unreacted fuel in the exhaust stream.

The fuel/air jets of the upper and lower sections are directed towards each other to form a flat stagnation plane. The sections are connected by four rods to maintain the jets centered and their axes collinear. The distance between the nozzle exit planes is fixed at $12 \mathrm{~mm}$, the same value as the nozzle diameter. When the fuel concentration is within flammable limits, a symmetric twin flame is formed on either side of the mid-plane. Ignition is provided manually with a retractable, modified butane lighter.

The burner plates directly exposed to the flames are water cooled to maintain their integrity and to minimize heat transfer back to the nozzle. Water flows through a copper tube coiled around the upper chamber of the burner to prevent the exhaust gases from preheating the upper section. A thermocouple is located on the centerline of the upper section just above the contraction nozzle to monitor the incoming mixture temperature. A thermocouple cold junction terminal block (National Instruments, SC-2070*) provides the ambient reference temperature reading, $\pm 0.5{ }^{\circ} \mathrm{C}$. Cooling is supplied by cold shop water which is filtered, divided, and directed by two rotameters into the burner face plates and cooling coil. A Panasonic Solid State Color Camera (WV-CD110A) provides an enlarged image to a video monitor for flame observation. A VCR is available to record the flame during the extinction event.

\footnotetext{
* Certain commercial equipment, instruments, or materials are identified in this paper in order to adequately specify the experimental procedure. Such identification does not imply recommendation or endorsement by the National Institute of Standards and Technology, nor does it imply that the materials or equipment used are necessarily the best available for the intended use.
} 


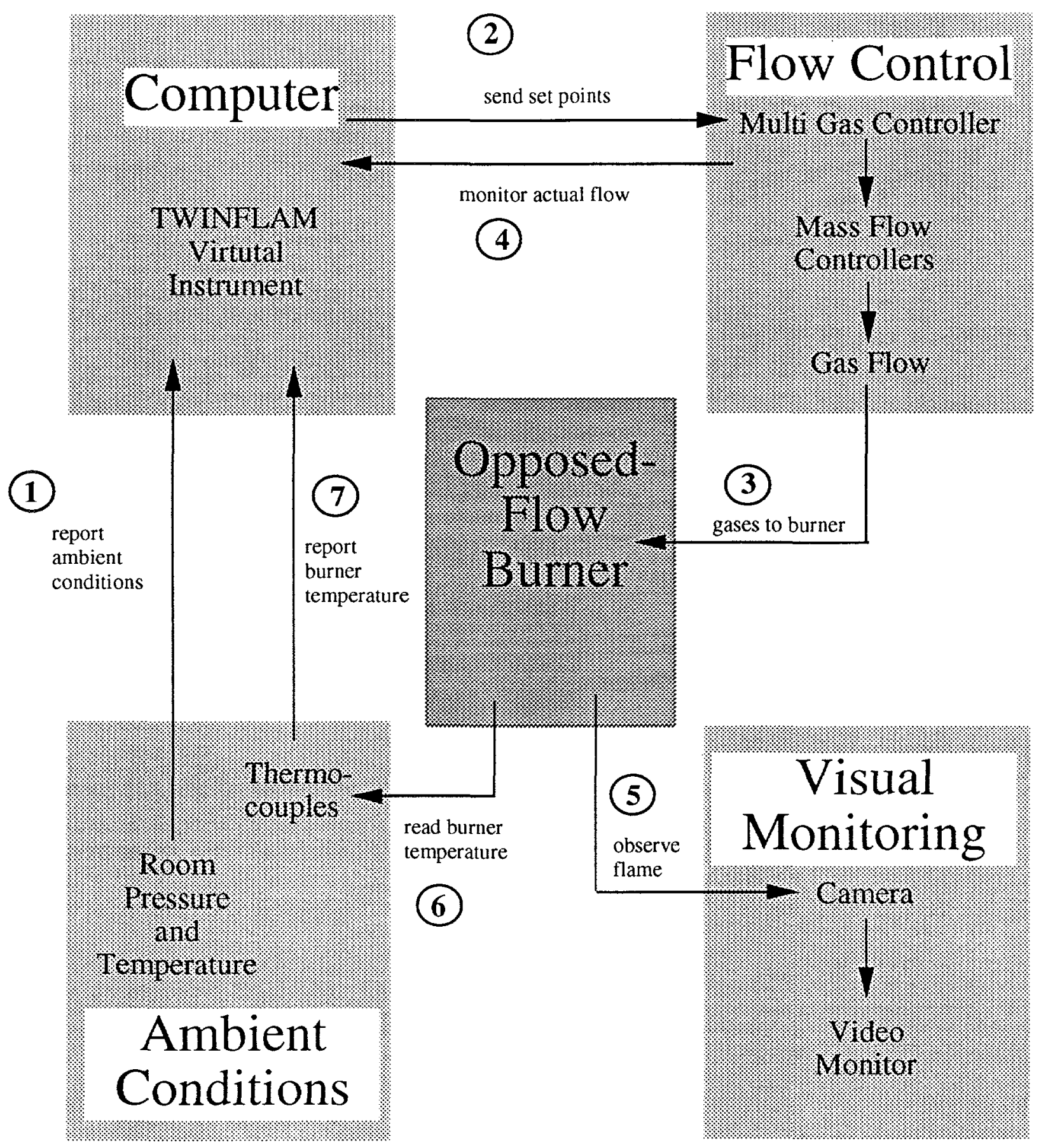

Figure 2: $\quad$ Systems diagram of opposed-flow burner facility. 


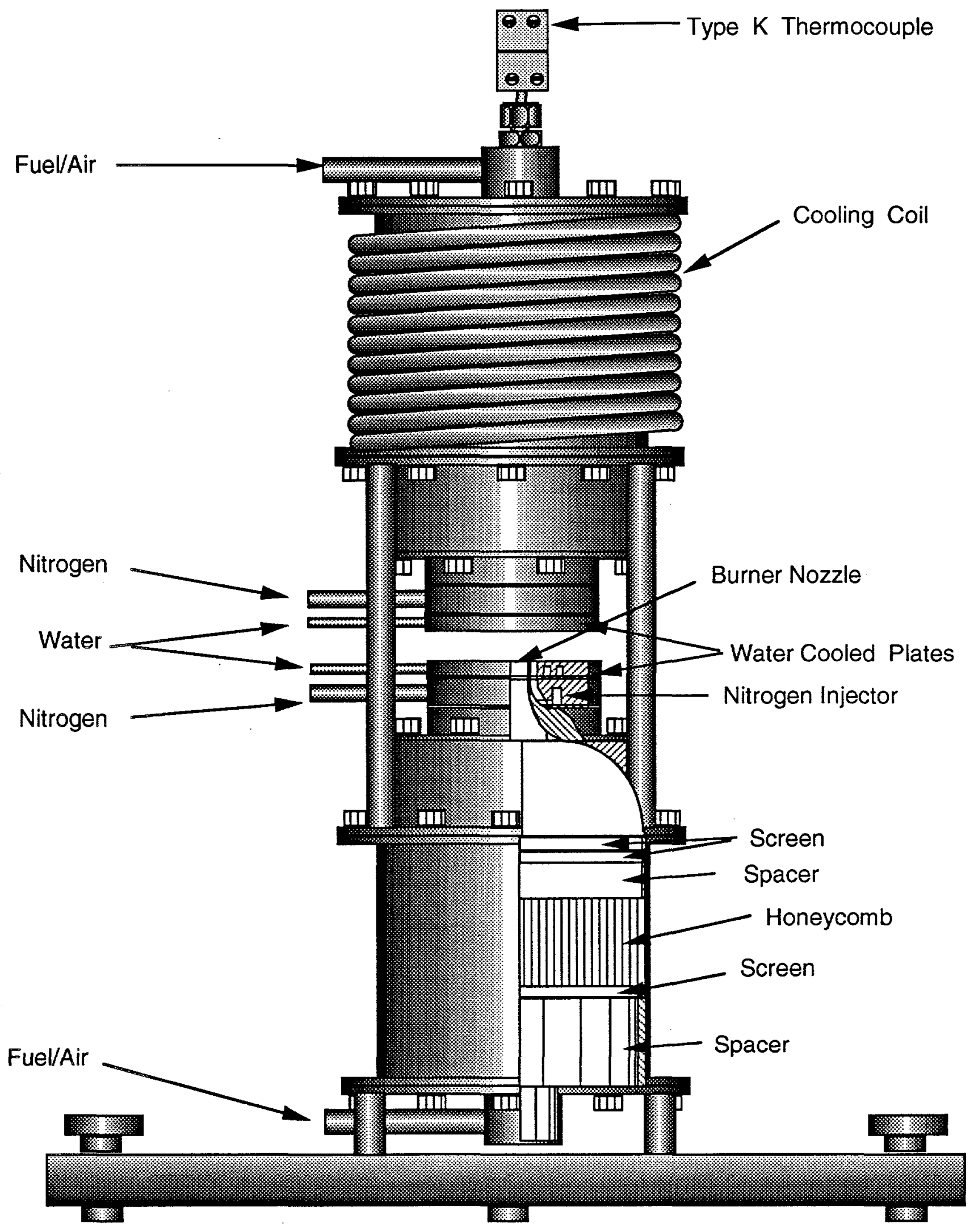

Figure 3: Opposed-flow burner assembly: two converging nozzles pointed toward the flame zone. 
Gas supply system: The gases are stored in individual cylinders at their respective room temperature vapor pressures. The R-32 (difluoromethane, $\mathrm{CH}_{2} \mathrm{~F}_{2}$ ) is from Allied Signal (Genetron 32), with a mass fraction of water and non-volatile residues claimed to be less $10^{-5}$ and non-condensable contaminates less than $1.5 \%$ by volume. The mass fraction of chlorides is below $10^{-6}$ and the acidity (in $\mathrm{mg} \mathrm{KOH} / \mathrm{g}$ ) is 0.0015 .

The methane (MG industries, research grade 4.5 ) has a minimum purity of $99.995 \%$ (by volume), with air and ethane the largest contaminates with mole fractions of $20 \times 10^{-6}$. The manufacturer claims the water mole fraction to be less than $5 \times 10^{-6}$.

The R-134a (1,1,1,2-tetrafluoroethane, $\left.\mathrm{C}_{2} \mathrm{H}_{2} \mathrm{~F}_{4}\right)$ is from Allied Signal (Genetron 134a) with a minimum assay of $99.8 \%$ by weight percent of R-134a and its isomers $(\leq 0.01 \%)$. The moisture mass fraction is claimed to be no more than $10^{-5}$.

The air (Matheson zero gas) is certified to have a mole fraction of $\mathrm{O}_{2}$ equal to $0.2110 \pm 0.0002$, and water and hydrocarbon levels below $10^{-6}$. The remaining components $\left(\mathrm{N}_{2}, \mathrm{Ar}\right.$, and $\left.\mathrm{CO}_{2}\right)$ are as taken from the atmosphere. The nitrogen shroud gas (MG Industries grade 4.8) is guaranteed pure to a mole fraction of 0.99998 .

Copper tubing, $6.4 \mathrm{~mm}$ in diameter, is used to transport the air, nitrogen and methane to individual mass flow controllers (MKS, Inc.). Table II lists the model numbers and flow ranges for each controller. The refrigerant is transported in stainless steel tubing. The air and fuel (either methane or R-32) are mixed at a tee beyond the flow controls, and delivered to the burner through $9.5 \mathrm{~mm}$ stainless steel tubing. Gas pressures into the mass flow controllers (MFCs) are regulated at $138 \mathrm{kPa} \pm 3 \mathrm{kPa}$ to standardize flow conditions. The fuel/air mixture is split between the upper and lower sections at the burner. Figure 4 is an overall schematic of the facility components, showing how the gas supply is controlled and connected to the burner.

Water vapor for the high humidity experiments is added by passing the air stream from the outlet of the mass flow controller through two glass bubblers $(2.2 \mathrm{~L})$ in series. Each bubbler is filled with $0.40 \mathrm{~L}$ of deionized water with $1.25 \mathrm{~kg}$ of dissolved $\mathrm{Mg}\left(\mathrm{NO}_{3}\right)_{2}$ salt. The magnesium nitrate is supplied by Fisher Scientific and has an assay value greater than $99.9 \%$. Greenspan (1977) has shown that at $25^{\circ} \mathrm{C}$ and $101 \mathrm{kPa}$, this salt solution equilibrates at a relative humidity of $52.9 \% \pm 0.2 \%$. The bubblers are placed in a room temperature water bath, and the humid air at the outlet passes through a particle trap to ensure no water drops remain suspended in the air stream. A fast response digital hygrometer from Fisher Scientific monitors changes in the relative humidity between experiments. The stated accuracy of the hygrometer is $\pm 2 \%$.

Table II: $\quad$ Mass flow controllers specifications

\begin{tabular}{c|c|c|c}
\hline MFC \# & Model Number & $\begin{array}{c}\text { Flow Range } \\
\text { (Standard L/min) }\end{array}$ & Calibrated Gas \\
\hline 1 & $1559 \mathrm{~A}-020 \mathrm{~L}-\mathrm{SN}-\mathrm{S}$ & $0.20-20.00$ & Air \\
2 & $1359 \mathrm{C}-10000-\mathrm{SN}$ & $0.10-10.00$ & $\mathrm{~N} 2$ \\
3 & $1359 \mathrm{C}-10000-\mathrm{SN}$ & $0.050-5.000$ & $\mathrm{R}-32$ \\
4 & $1359 \mathrm{C}-01000-\mathrm{SN}$ & $0.0020-0.2000$ & $\mathrm{R}-125$ \\
\hline
\end{tabular}



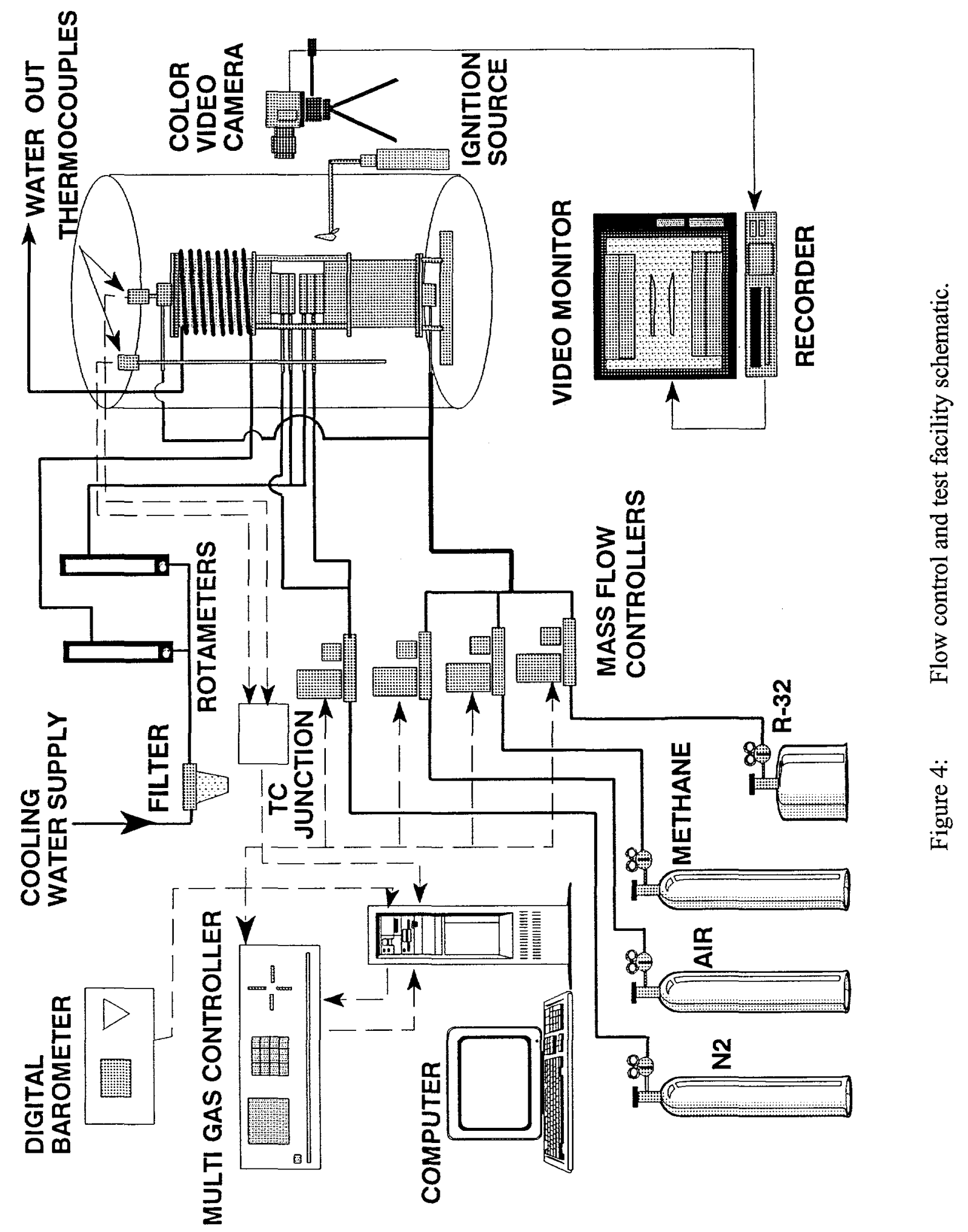
Flow control, data acquisition, and flow controller calibration: The flows of the individual gas streams are controlled through an MKS, Inc., Multi Gas Controller type 647B. A special modification to the $647 \mathrm{~B}$ has increased the resolution of the control from $0.1 \%$ to $0.01 \%$ of the full scale of flow of each MFC. This instrument powers, reads, and controls the four mass flow controllers listed in the above table. Each MFC measures flow by maintaining a constant temperature heated tube with a known fraction of the gas flowing through it. The MFC measures the voltage required to keep the tube at the constant temperature. The voltage necessary, between 0 and $5 \mathrm{~V}$, represents a fraction of the full scale flow of the MFC. A proportioning control valve adjusts the flow based on the difference between the measured flow value and the desired set point.

The mass flow controllers were calibrated by the manufacturer with nitrogen and adjusted with multiplicative correction factors for the different gases used. The correction factors account for differences in density, specific heat, and molecular structure relative to nitrogen. The correction factors are 1.00 for air, 0.72 for $\mathrm{CH}_{4}, 0.61$ for R-32, 0.27 for R-125, and 0.30 for R-134a.

This conversion provides an estimate of the correction necessary for different gases. A critical review of mass flow controllers and gas correction factors performed at NIST (Tison, 1996) showed that calibration with each gas is required to provide the optimum accuracy of the MFCs. Consequently, all MFCs were recalibrated with the exact gas used during testing. The calibration reference used was an Optiflow 730 soap bubble meter. This flow meter was tested using the NIST standard piston prover (Pitts et al., 1995) and has been shown to be accurate to within $1 \%$ over its entire range, $0.1 \mathrm{~L} / \mathrm{min}$ to $25 \mathrm{~L} / \mathrm{min}$. With a stated repeatability of the MFCs at $\pm 0.2 \%$ of full scale, a linear fit from multiple calibration points corrects the control to an accuracy of $\pm 2 \%$.

The dry air flow is measured upstream of the bubblers for the high humidity experiments. The addition of moisture increases the volume flow by about $2 \%$ for $50 \%$ relative humidity at ambient conditions. Ideally, a saturated mixture of pure deionized water and $\mathrm{Mg}\left(\mathrm{NO}_{3}\right)_{2}$ equilibrates to a relative humidity of $52.9 \%$ at $25{ }^{\circ} \mathrm{C}$. In a flowing system the continuous introduction of dry air carries with it a small but constant amount of $\mathrm{CO}_{2}$. The purity of the solution decreases as the $\mathrm{H}_{2} \mathrm{O}$ and $\mathrm{CO}_{2}$ react to form $\mathrm{H}_{2} \mathrm{CO}_{3}$, reducing the effective relative humidity. The impact of the $\mathrm{CO}_{2}$ absorption is initially dramatic, but levels off once the system is conditioned with $\mathrm{CO}_{2}$. The actual relative humidity is $43 \% \pm 2 \%$, as measured by the digital hygrometer, for all the tests reported here.

Experimental control is provided by a $486 / 66 \mathrm{MHz}$ personal computer with $12 \mathrm{MB}$ RAM, operating with National Instruments' LabVIEW 3.1.1 on Microsoft Windows 3.1. An IEEE Standard 488 GPIB talker/listener interface communicates with the mass flow controllers. A National Instrument Data Acquisition Card (AT-MIO-16E-10) with eight differential 12 bit inputs collects readings from the thermocouples (Omega, type $\mathrm{K}$ ), the cold junction terminal block, and a digital barometer (Druck, 145 DPI). The computer monitors ambient, burner, and flow conditions while controlling flow values through a specialized virtual instrument called TWINFLAM, programmed specifically for this project. Given a flame condition, TWINFLAM calculates the appropriate gas flow values, corrects for ambient conditions, and sends signals via the Multi Gas Controller to the four mass flow controllers. 


\section{Experimental Results and Discussion}

A typical experiment using methane $\left(\mathrm{CH}_{4}\right)$ in dry air is described below to indicate how the components in the opposed-flow facility work together when evaluating an extinction point. The results for the $\mathrm{CH}_{4}$ /dry air, R-32/dry air, R-32/humid air, and R-134a/dry air follow. A brief discussion of the influence of external test parameters concludes the section.

Methane test description: To prepare the system for a test, the cooling water and the video monitor are turned on. The mass flow controllers are zeroed. Then the gas lines are pressurized. On the computer, LabVIEW is loaded to run the virtual instrument TWINFLAM.

The initial conditions for a $\mathrm{CH}_{4} /$ air test are chosen from known flammability limits. Conditions near stoichiometric and with low flow are avoided, because the high flame speed causes the flame to flashback into the burner sections. If the conditions are too close to the flammability limit, it is not possible to stabilize a flame. Once a condition has been found which leads to a steady flame, it is not difficult to change the conditions gradually to find alternate stable conditions so that other strain rates can be tested. For example, a strain rate of $50 \mathrm{~s}^{-1}$ and an equivalence ratio of 0.55 provides a stable flame. These initial values are represented by an " $\mathrm{x}$ " in the small box on the schematic drawing of the flammability map for $\mathrm{CH}_{4}$ in Figure 5.

Once the initial conditions are entered into the computer, TWINFLAM turns on the air and then the fuel, and monitors the settings continuously. The flame is lit with the butane lighter and allowed to stabilize. On the video monitor, two thin blue flames are visible. They are approximately $20 \mathrm{~mm}$ across with a gap on the order of a millimeter in-between. The $\mathrm{N}_{2}$ shroud is then initiated, lifting the edge of the flame and truncating the outer circumference. Figure 6 shows the twin flames schematically.

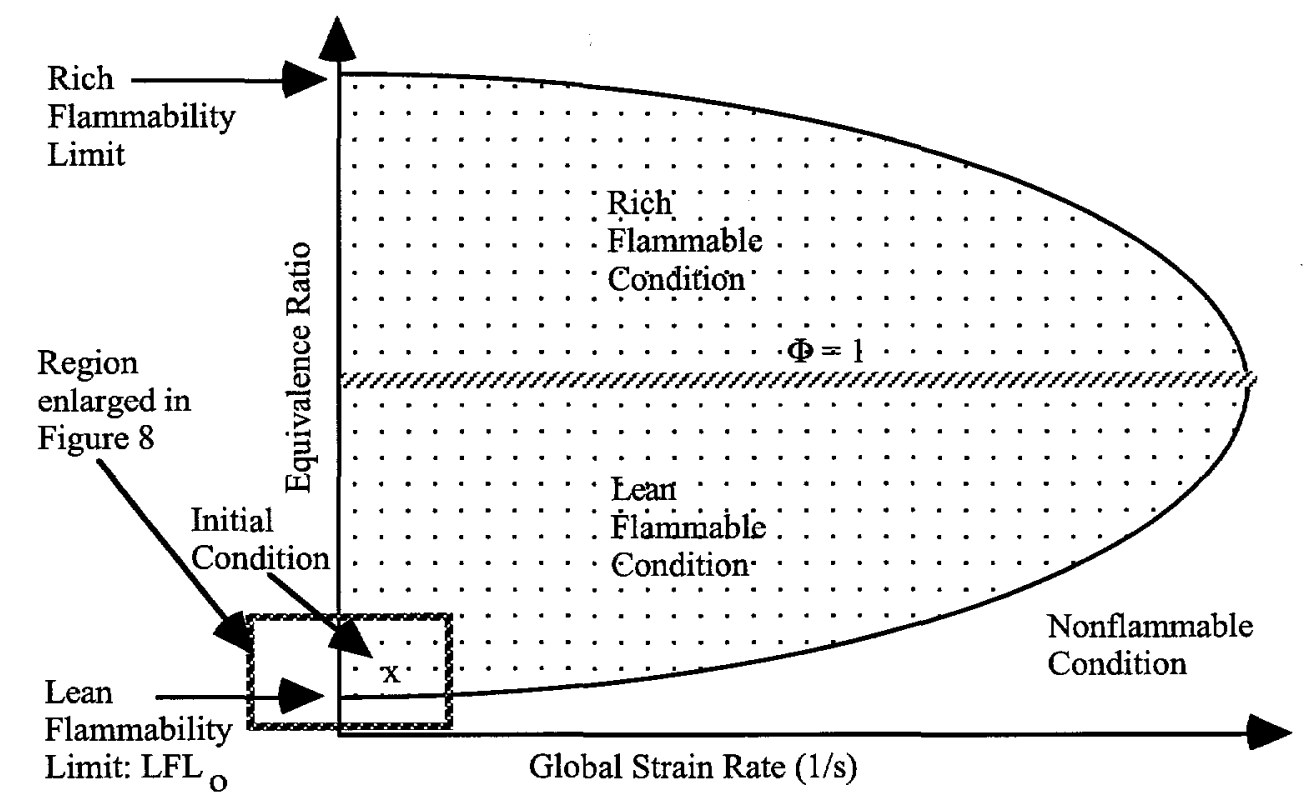

Figure 5: $\quad$ General flammability map for $\mathrm{CH}_{4} /$ air mixtures as a function of global strain rate. 


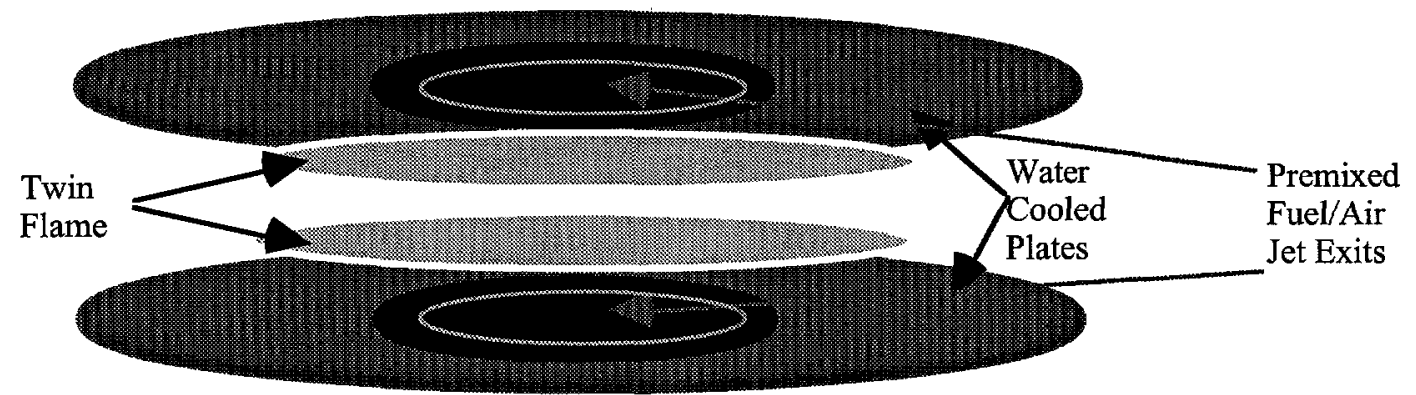

Figure 6: Diagram of an opposed-flow flame; burner face plates are shown.

The equivalence ratio is reduced in small increments, and the flame is stabilized again and again until extinction. For a sample test, the equivalence ratio is plotted as it changes in time in Figure 7. Near extinction, the step change is reduced to increase the resolution at the extinction point. For the test shown in Figure 7, extinction occurred at an equivalence ratio of 0.525 and a global strain rate of $50.0 \mathrm{~s}^{-1}$.

Methane results: Figure 8 is a plot of multiple extinction points taken with global strain rates between 30 and $70 \mathrm{~s}^{-1}$. Together they define the low strain, lean perimeter of the flammability map for $\mathrm{CH}_{4}$ in dry air, as originally described in Figure 5. During these tests the ambient laboratory conditions were $98.8 \mathrm{kPa}$ and $27^{\circ} \mathrm{C}$. The line described by

$$
\Phi_{x}=0.494+0.00064 \cdot K
$$

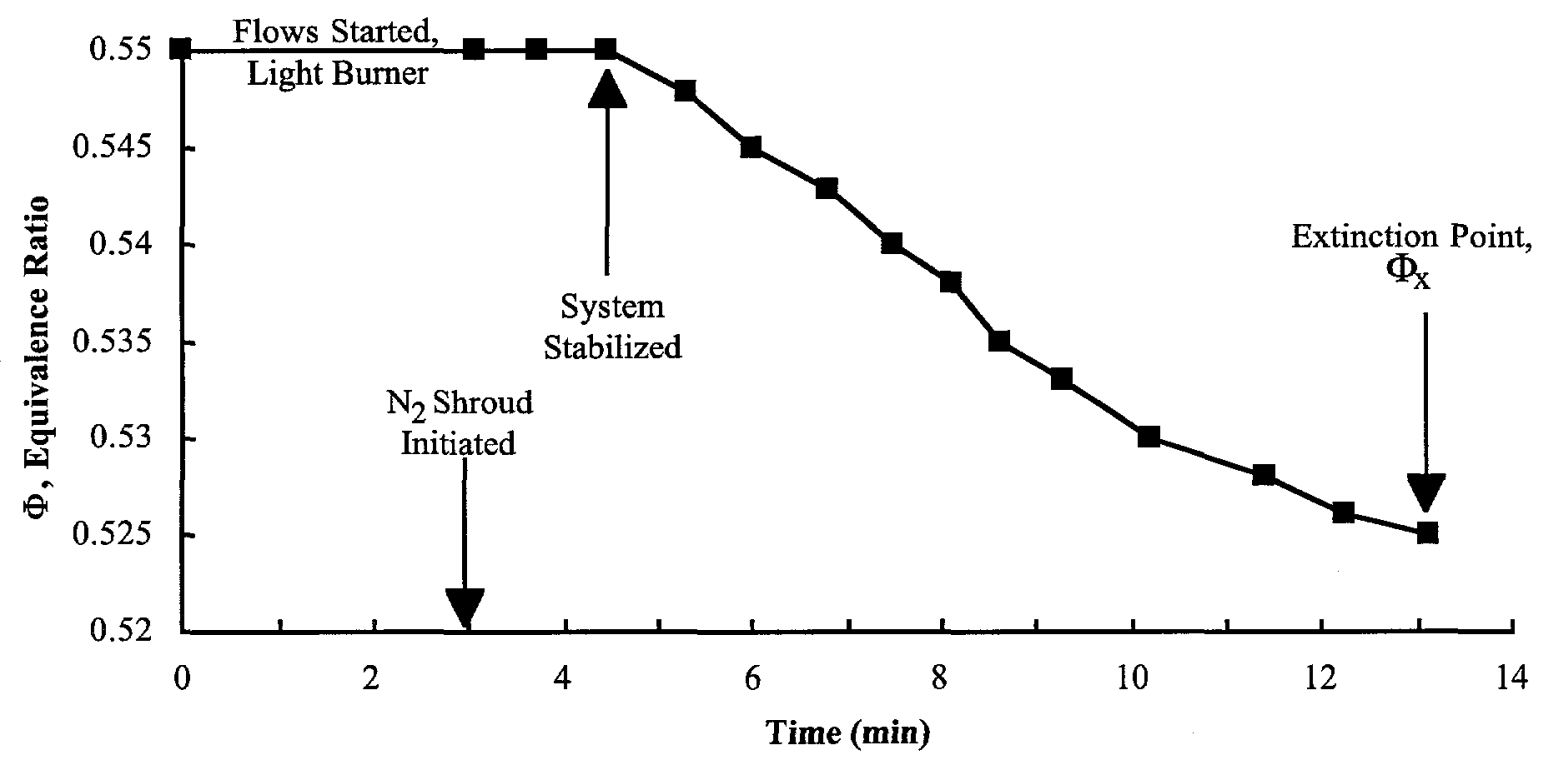

Figure 7: Progression of a $50 \mathrm{~s}^{-1} \mathrm{CH}_{4} /$ dry air test, showing the equivalence ratio as a function of time. 


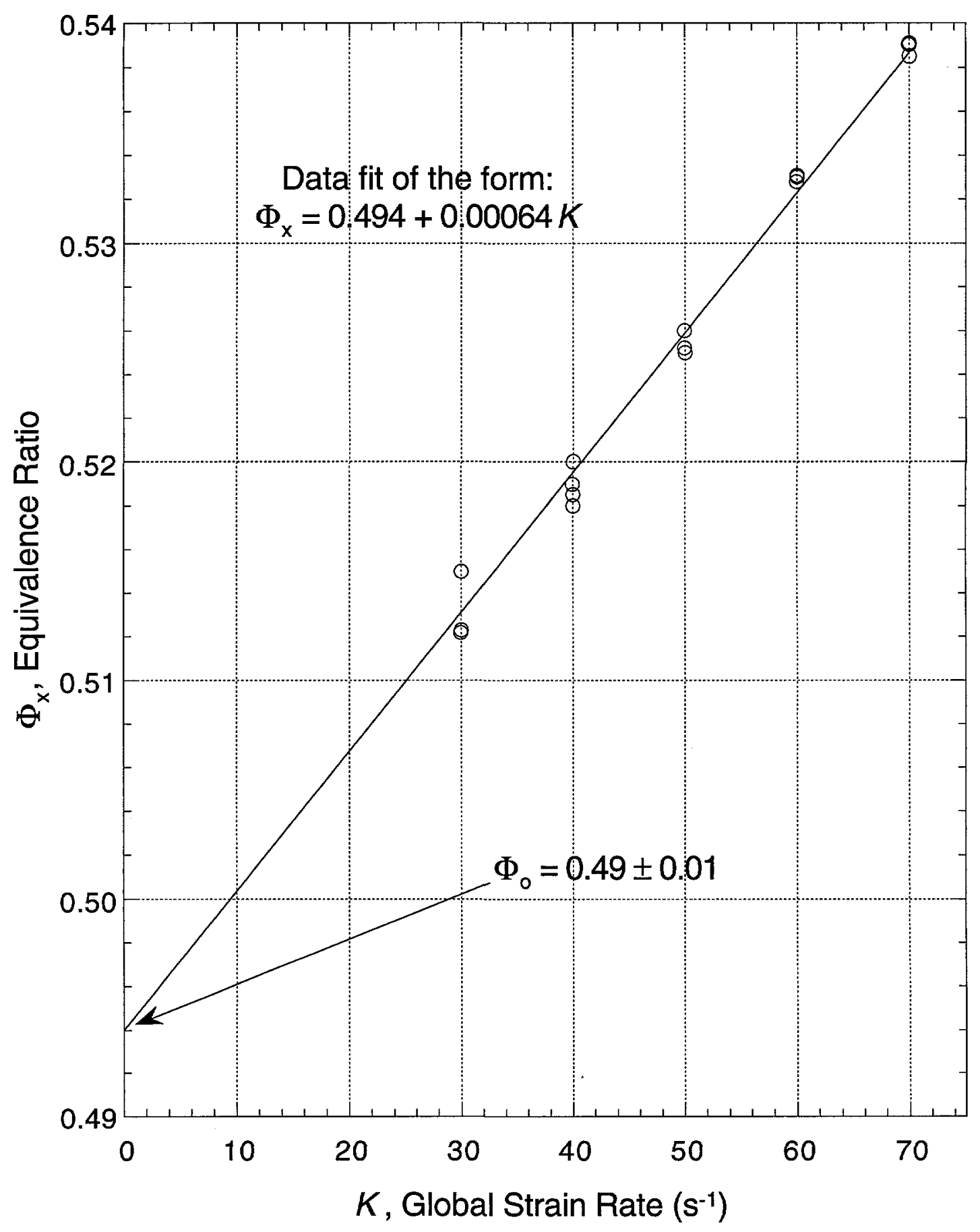

Figure 8: Lean extinction points for different global strain rates for $\mathrm{CH}_{4}$ in dry air. 
was derived from a non-least-squares fit of the flow values for the fuel and air, described in detail in the Appendix. A traditional least squares analysis assumes independence between the abscissa and ordinate, but because both $\Phi$ and $K$ are functions of the fuel and air flows, the more simplistic analysis would have been inappropriate. The intercept with the $\Phi$ axis occurs at $\Phi_{0}=0.494$. This intersection point corresponds to the $\mathrm{LFL}_{\mathrm{o}}$ of $\mathrm{CH}_{4}$ in dry air of $4.9 \%$ by volume. The uncertainty in the intercept typically is a function of the standard deviation of the fit (see Appendix), which in this case is $0.2 \%$ of the intercept value. This low uncertainty indicates the high repeatability of each data point and reinforces the assumption that the fit is truly linear in this regime.

The total uncertainty in the intercept, however, is dependent upon the uncertainty derived from the fit and the uncertainty in the flow calibrations. Analysis of results from several independent experiments using different sets of mass flow controllers, different calibration instruments, etc. would define a total uncertainty which would incorporate both uncertainty sources. To model these independent experiments, 100 simulated data sets with random error, normally distributed over the known uncertainty in the flows $( \pm 2 \%)$ were computed and fit to evaluate $\Phi_{0}$. Twice the standard deviation of the average of these intercepts provides a more realistic estimate of the total uncertainty for $\Phi_{\mathrm{o}}$ with a $95 \%$ confidence interval: \pm 0.01 .

Comparison of methane results: The motivation behind the methane testing is to provide a comparison between the $\mathrm{LFL}_{\mathrm{o}}$ from the NIST opposed-flow burner and published results using other techniques. These tests demonstrate that the $\mathrm{LFL}_{\mathrm{o}}$ for $\mathrm{CH}_{4}$ defined with this burner and method provides excellent agreement with published values. Table III lists a variety of lean flammability limits published over the last 30 years. Our value falls comfortably in the middle of the range of published values.

The lowest value in the table, $4.0 \%$ by volume, represents an extreme value based on a test which measures the extinction concentration of the tip of a flame while the mixture is encircled by another flame. Sorenson et al. (1975) describe it as, "completely surrounded by burning gases...there may in fact be some heat addition to the mixture," and they state that it is "...not intended to supplant standard flammability techniques that measure the flame's ability to propagate..." Based on these comments, this value may not be a realistic comparison point. The highest value in the table was found during Phase I of this project. This value was determined from points which had an uncalculated uncertainty and were taken over a much wider range of strain rates. Without more understanding of this preliminary result, this value also may be a less relevant comparison point. Neglecting these two points, the remaining values fall between $5.1 \%$ and $4.7 \%$, which favorably bound this Phase II value of the $\mathrm{LFL}_{\mathrm{o}}$ for $\mathrm{CH}_{4}$ in dry air: $4.9 \% \pm 0.1 \%$ by volume.

R-32 testing and results: The differences between running the $\mathrm{R}-32$ tests and the $\mathrm{CH}_{4}$ are few. Both are lit at stable conditions above the lean extinction limit. For the test operator, the most significant difference between the two fuels is that the primary byproduct (as described in the equilibrium calculation) of $\mathrm{CH}_{2} \mathrm{~F}_{2}$ combustion is $\mathrm{HF}$, a toxic and corrosive acid gas. For this reason, all tests are performed inside a plexiglas tube and within a chemical hood. The other significant difference between these fuels is that the narrower range of stable, flammable conditions for R-32 makes it more difficult to light the twin flame. Because of the lower flame 
Table III: $\quad$ Lean flammability limits of methane $\left(\mathrm{CH}_{4}\right)$

\begin{tabular}{l|c|l|l|c|c}
\multicolumn{1}{c|}{ Author(s) } & Year & \multicolumn{1}{c|}{ Method } & \multicolumn{2}{c|}{ Conditions } & \multicolumn{2}{c}{ CH4, Lean Limit } \\
$\%$ by volume
\end{tabular}

speed the R-32 flame does not have a problem with flashback. The R-32 flame appears blue with a white tinge. It is somewhat thicker and is, overall, more luminescent than the $\mathrm{CH}_{4}$ flame, even when the conditions are near an extinction point.

The results from the R-32 tests demonstrate precision and consistency comparable to the $\mathrm{CH}_{4}$ results. In Figure 9, extinction points are plotted versus the global strain rates for R-32 in dry air at $100.1 \mathrm{kPa}$ and $26{ }^{\circ} \mathrm{C}$. The intercept value is 0.78 with a $95 \%$ confidence interval of \pm 0.04 . This corresponds to an $\mathrm{LFL}_{\mathrm{o}}$ for $\mathrm{R}-32$ in dry air of $14.0 \% \pm 0.8 \%$ by volume. The fundamental differences in these two types of fuels is evident in a comparison of Figures 8 and 9. Over the same range of strain rates the R-32 tests cover more than four times the range of the stoichiometry. At the highest global strain rate tested, $70 \mathrm{~s}^{-1}$, the extinction equivalence ratio for R-32 equals 1.0 , while for $\mathrm{CH}_{4}$ it is only 0.54 . These values, along with the differences between the slopes and the intercepts, emphasize that R-32 is a much weaker fuel and is flammable over a much narrower range on the lean side.

Table IV shows a comparison of the lean flammability limits of R-32 in dry air from different authors and flammability techniques. The range of values is much wider than those published for $\mathrm{CH}_{4}$. The Phase II LFL $\mathrm{L}_{\mathrm{o}}$ for R-32 in dry air, $14.0 \% \pm 0.8 \%$ by volume, falls in the middle and agrees with values published by Deklava (1993) using both a 5 and 12 liter ASTM E 681 device (1994). The range of values shown in Table IV can be attributed in part to different techniques, but the primary reason for the discrepancies is the difficulty of measuring a weakly flammable 


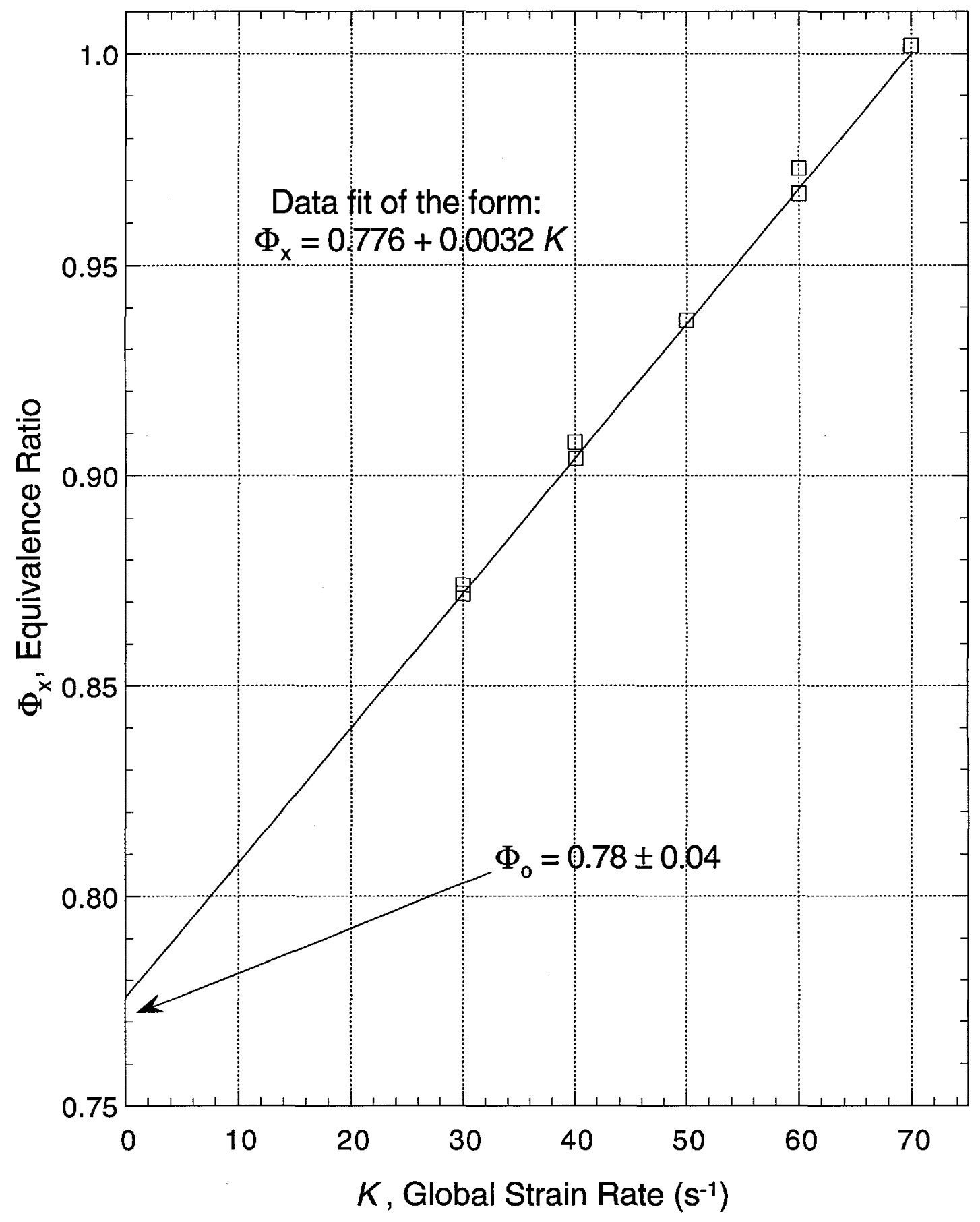

Figure 9: Lean extinction points for different global strain rates for R-32 in dry air. 
Table IV: $\quad$ Lean flammability limits of R-32 $\left(\mathrm{CH}_{2} \mathrm{~F}_{2}\right) /$ air mixtures

\begin{tabular}{|c|c|c|c|c|c|}
\hline \multirow[t]{2}{*}{ Author(s) } & \multirow[t]{2}{*}{ Year } & \multirow[t]{2}{*}{ Method } & \multirow[t]{2}{*}{ Conditions } & \multicolumn{2}{|c|}{ R-32, Lean Limit } \\
\hline & & & & $\%$ volume & $\Phi$ \\
\hline $\begin{array}{l}\text { Dekleva, Lindley, } \\
\text { Powell }\end{array}$ & 1993 & $5 \mathrm{~cm}$ tube $(\mathrm{ICI})$ & hot wire & 18.9 & 1.11 \\
\hline Richard, Shankland & 1992 & 4 liter tube & match & 15 & 0.84 \\
\hline $\begin{array}{l}\text { Dekleva, Lindley, } \\
\text { Powell }\end{array}$ & 1993 & ASTM E-681, 5 liter & hot wire & 14.6 & 0.81 \\
\hline Grob, D. & 1991 & ASTM E-681, 12 liter & hot wire & 14.6 & 0.81 \\
\hline Richard, Shankland & 1992 & ASTM E-681, 5 liter & hot wire & 14.2 & 0.79 \\
\hline this publication & 1996 & Twin flame, LFLo & $\mathrm{H}=\mathrm{D}, \Delta \mathrm{T}<1{ }^{\circ} \mathrm{C}$ & $14.0 \pm 0.8$ & $0.78 \pm 0.04$ \\
\hline $\begin{array}{l}\text { Dekleva, Lindley, } \\
\text { Powell }\end{array}$ & 1993 & ASTM E-681, 5 liter & hot wire & 14 & 0.77 \\
\hline $\begin{array}{l}\text { Dekleva, Lindley, } \\
\text { Powell }\end{array}$ & 1993 & ASTM E-681, 12 liter & match & 14 & 0.77 \\
\hline $\begin{array}{l}\text { Dekleva, Lindley, } \\
\text { Powell }\end{array}$ & 1993 & Autoclave, 8 liter & hot wire & 13.6 & 0.75 \\
\hline Richard, Shankland & 1992 & ASTM E-681, 5 liter & spark & 13.5 & 0.74 \\
\hline Ohnishi, H. & 1993 & ASTM E-681, 5 liter & paper match & 13 & 0.71 \\
\hline Richard, Shankland & 1992 & ASTM E-681, 5 liter & match & 12.7 & 0.69 \\
\hline $\begin{array}{l}\text { Womeldorf, King, } \\
\text { Grosshandler }\end{array}$ & 1995 & Twin flame, LFLo & $\begin{array}{l}\mathrm{H}<\mathrm{D}, \mathrm{D}=24 \mathrm{~mm}, \\
\text { screened straight nozzle }\end{array}$ & 12 & 0.65 \\
\hline
\end{tabular}


fuel. The relatively steep slope shown in Figure 9 reflects the fact that if a test provides a slightly different strain condition, the impact on extinction is large; a change in strain rate of $20 \mathrm{~s}^{-1}$, for example, causes a change of $1.3 \%$ by volume R-32 in dry air. By comparison, the same change in strain causes a change of only $0.13 \%$ by volume for the $\mathrm{LFL}_{\mathrm{o}}$ of $\mathrm{CH}_{4}$.

The R-32 flammability experiments were repeated using air with a relative humidity of $43 \% \pm 2 \%$. $\Phi_{\mathbf{X}}$ is plotted as a function of the global strain rate for the tests in Figure 10. The difference between the intercept values for the dry and humid tests fall within the experimental uncertainty. The extrapolated value for the $\mathrm{LFL}_{\mathrm{o}}$ is $14.1 \% \pm 0.6 \%$ by volume. Because the fluorine to hydrogen ratio is unity in R-32, the flame speed is not particularly sensitive to the amount of humidity in the air; that is, any enhancement created by an increase in the $\mathrm{OH}$ and/or $\mathrm{H}$ mole fraction is offset by the energy absorbed by the additional water molecules. This effect is also demonstrated in the theoretical flame calculations discussed in the next section.

R-134a in dry air: Several attempts were made to evaluate the $\mathrm{LFL}_{\mathrm{o}}$ for $\mathrm{R}-134 \mathrm{a}\left(\mathrm{C}_{2} \mathrm{H}_{2} \mathrm{~F}_{4}\right)$ in dry air at room temperature and ambient pressure conditions. Only when $\mathrm{CH}_{4}$ was added to the mixture of R-134a and dry air was it possible to support a flame. The flame burned when $\Phi=1.0$ (based upon the $\mathrm{R}-134 \mathrm{a} /$ air ratio) with $\mathrm{CH}_{4}$ added to the flow. Because the mixture was well below the lean limit of $\mathrm{CH}_{4}$ in air, it is apparent that the $\mathrm{R}-134 \mathrm{a}$ adds energy to the flame, even though R-134a by itself did not support a flame at these conditions. For a global strain rate as low as $30 \mathrm{~s}^{-1}$, it was not possible to reduce the amount of $\mathrm{CH}_{4}$ to less than $2 \%$ of the total volume flow and still support a flame.

Systematic uncertainty effects: The Phase II results for the $\mathrm{CH}_{4}$ and $\mathrm{R}-32$ are different from the preliminary results reported in Phase I. The exact cause is unclear. Systematic uncertainty effects that were detected during the data analysis of Phase II may suggest some explanations. The inlet flow temperatures were not measured during the Phase I preliminary study. However in Phase II, it was observed that a difference in temperature between the upper and lower gas streams noticeably impacted the extinction points. Likewise, the detailed analysis of the residuals of the data fits, which was not performed during Phase I, revealed some sensitivity to variations in the ambient barometric pressure.

Plotting the residuals from the curve fit versus the difference in temperature between the upper and lower jets, demonstrated the influence of $\Delta \mathrm{T}$ on the data. For example, initially a wide range (up to $25{ }^{\circ} \mathrm{C}$ ) of temperature variations was recorded for the methane data. Inspection of the repeatability of each point indicated that there was a wider range of values than was expected given the overall accuracy of the flow control system. By plotting the residuals versus $\Delta \mathrm{T}$, the increasing discrepancies between the fit and those points with elevated temperature was evident. After eliminating from consideration all points with a $\Delta \mathrm{T}$ greater than $5^{\circ} \mathrm{C}$, it was still clear that there was a slight downward drift due to the heating of the burner. When the $\Delta \mathrm{T}$ cutoff was set at $1{ }^{\circ} \mathrm{C}$ or less, the residual scatter fell evenly about the curve fit, indicating that the impact was less significant than the experimental repeatability. Consequently, no data were considered if the temperature of the incoming gas from the upper burner was more than $1{ }^{\circ} \mathrm{C}$ hotter than the lower gas temperature. The magnitude of the $\Delta \mathrm{T}$ may not be representative of the actual $\Delta \mathrm{T}$ between the two jets because the thermocouple is located $70 \mathrm{~mm}$ upstream of the upper burner exit and the downstream temperature may be higher. 


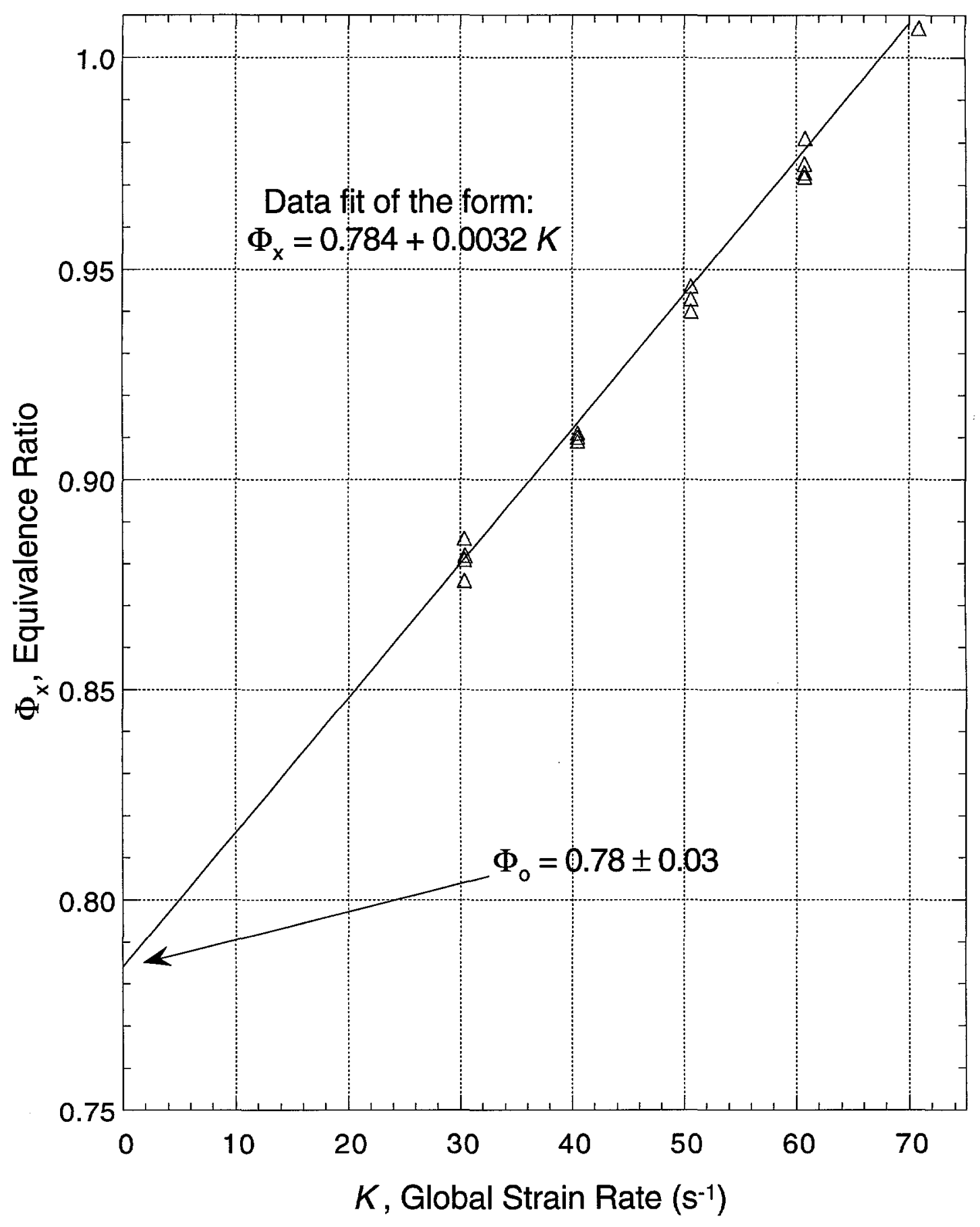

Figure 10: Lean extinction points for different global strain rates for R-32 in air with a relative humidity of $43 \% \pm 2 \%$. 
Generally the local barometric pressure in Gaithersburg, MD during testing fell in the range of $99.7 \pm 1.3 \mathrm{kPa}$. The analysis of the residuals showed a weak trend upward, indicating a reduction in flammability with decreasing pressure. The trend, however, was less than the uncertainty in the data fit. On one day the pressure dropped to $97.8 \mathrm{kPa}$ and the residuals from that day's tests clearly illustrated that this effect, though small, was not an artifact of random scatter. The effect of pressure on flammability has been documented by others, including Deklava et al. (1993). Given that the atmospheric pressure is uncontrolled, the data under consideration have been limited by bounding the acceptable range of barometric pressure to be within $99.7 \mathrm{kPa} \pm 1.3 \mathrm{kPa}$. 


\section{Theoretical Flame Calculations}

Laminar flame speed: Laminar flame speed, $\mathrm{v}_{0}$, is a physical parameter that is an indicator of the flammability limits, the enthalpy of combustion, and the rate of heat release of a fuel and air mixture (Barnard and Bradley, 1985; Glassman, 1977). A lesser hazard is posed by a refrigerant that has a small value for flame speed because this implies a narrower flammability limit, a lower enthalpy of combustion, a slower rate of heat release, or some combination of these three properties. The flame speed is also amenable both to experimental measurement and theoretical calculation as a function of the initial mixture conditions.

A steady, planar, laminar flame is established (following a short transient period) when a mixture of fuel and air is exposed to a sufficiently energetic ignition source. If one chooses the flame front as the frame of reference, the premixed reactants (refrigerant plus air at $25{ }^{\circ} \mathrm{C}$ and $101 \mathrm{kPa}$ ) can be thought of as traveling into the flame from the negative direction at a speed $v_{0}$ and the products of combustion as leaving the flame in the positive direction at the equilibrium flame temperature $T_{\mathbf{f}}$. Assuming the ideal gas relationship holds, the speed of the products will be greater than $v_{0}$ by the factor $T_{f} / 298 \cdot X_{f} / X_{o}$, where $X$ is the original (o) and final (f) number of moles in the reactants and products, respectively.

The conservation of energy, momentum, total mass, and identity of atoms applies across the flame. Intermediate and final product species are formed in the flame as dictated by the chemical kinetics, and changes in temperature through the flame result from the net exothermic release of energy in the multitude of individual elementary chemical reactions. For a steady onedimensional flame, the conservation relations yield a set of ordinary differential equations, with the mass flux through the flame being an eigenvalue. The flame speed follows directly from this eigenvalue.

Chemical kinetics mechanism: The number of elementary chemical kinetic steps necessary to describe the combustion of a fuel increases with the number of atomic constituents and the molecular complexity of the fuel. Oxidation of the simple fuel hydrogen involves the following critical chain reactions:

$$
\begin{gathered}
\mathrm{H}+\mathrm{O}_{2} \Leftrightarrow \mathrm{OH}+\mathrm{O} \\
\mathrm{H}_{2}+\mathrm{O} \Leftrightarrow \mathrm{OH}+\mathrm{H} \\
\mathrm{H}_{2}+\mathrm{OH} \Leftrightarrow \mathrm{H}_{2} \mathrm{O}+\mathrm{H}
\end{gathered}
$$

A complete mechanism for the $\mathrm{H}_{2} / \mathrm{O}_{2}$ system consists of about 22 additional reactions operating in both the forward and reverse directions.

The $\mathrm{H}, \mathrm{O}$ and $\mathrm{OH}$ radicals play key roles in the high temperature oxidation of all hydrocarbontype fuels, with the primary pathway for $\mathrm{CO}_{2}$ production involving the $\mathrm{OH}$ radical directly; i.e.,

$$
\mathrm{CO}+\mathrm{OH} \Leftrightarrow \mathrm{CO}_{2}+\mathrm{H}
$$


In the case of methane combustion, carbon monoxide is formed from the parent fuel in a sequence of steps: $\mathrm{CH}_{4} \rightarrow \mathrm{CH}_{3} \rightarrow \mathrm{H}_{2} \mathrm{CO} \rightarrow \mathrm{CO}$.

Comprehensive methane oxidation mechanisms have been developed for different applications, typically containing the $\mathrm{H}_{2} / \mathrm{O}_{2}$ system and over 50 reactions (in the forward and reverse directions) involving single carbon molecules. Modeling methanol $\left(\mathrm{CH}_{3} \mathrm{OH}\right)$, which is formed as an intermediate species from $\mathrm{CH}_{4}$ oxidation, requires another 80 or so reactions. Except under quite lean conditions, $\mathrm{C}_{2}$-and $\mathrm{C}_{3}$-species can play a significant role in the combustion process, adding over 50 more two-way reactions to the mechanism. In all, 239 discrete chemical kinetic steps have been used in the current calculations to determine the structure of a methane/air flame, based heavily upon the Miller-Bowman (1989) mechanism with nitrogen chemistry removed. Modifications to the Miller-Bowman mechanism are those documented by Burgess et al. (1995).

Table V summarizes the contributions of the individual mechanisms to the 842 total reactions used to model the $\mathrm{C} / \mathrm{H} / \mathrm{F} / \mathrm{O}$ chemistry. Table VI lists the 83 different species that are considered when fluorine is added to the complete $\mathrm{CH}_{4}$ /air mechanism. An additional six reaction steps are required to model $\mathrm{H} / \mathrm{F} / \mathrm{O}$ interactions, another 150 steps are necessary to handle the interactions with $\mathrm{C}_{1}$ compounds, and $\mathrm{C}_{2}$ reactions add another 447 .

Numerical premixed flame model: The set of differential equations governing the behavior of a steady, laminar, one-dimensional flame can be solved using a numerical model developed by Sandia National Laboratories (Kee et al., 1985) that has at its heart a chemical kinetics package called CHEMKIN (Kee et al., 1980). A detailed explanation of these codes will not be provided here since their structure is well documented in the above-referenced Sandia reports.

The premixed flame code has a number of options which control the calculation procedure and can impact the predicted species mole fractions, temperature profile, and flame speed. In the current study the flame is assumed to be freely propagating (FREE) with the temperature profile resulting from the explicit solution of the coupled energy equation (ENRG). The secondary

Table V: $\quad$ Components of chemical kinetic mechanism
A. hydrogen/oxygen system ( 25 two-way reactions)
B. methane oxidation (component $\mathrm{A}+65$ additional two-way reactions)
C. methanol oxidation ( $\mathrm{B}+85$ additional two-way reactions)
D. $\mathrm{C}_{2}$ hydrocarbon oxidation chemistry $(\mathrm{C}+64$ additional two-way reactions $)$
E. hydrogen/fluorine/oxygen system ( $\mathrm{A}+6$ additional two-way reactions)
F. $\mathrm{C}_{1}$ hydrofluorocarbon oxidation chemistry ( $\mathrm{D}+\mathrm{E}+150$ additional two-way reactions)
G. $\mathrm{C}_{2}$ hydrofluorocarbon oxidation chemistry ( $\mathrm{F}+447$ additional two-way reactions) 
Table VI: $\quad$ Species included in CHEMKIN calculations

nitrogen, oxygen:

$$
\begin{array}{lll}
\mathrm{N}_{2} & \mathrm{O}_{2} & \mathrm{O}
\end{array}
$$

hydrogen/oxygen:
$\mathrm{H}_{2}$
$\mathrm{H}_{2} \mathrm{O}$
$\mathrm{H}_{2} \mathrm{O}_{2}$
$\mathrm{HO}_{2}$
$\mathrm{OH}$
$\mathrm{H}$

hydrocarbons and fragments (up to $\mathrm{C}_{2}$ ):

$\begin{array}{llll}\mathrm{CH}_{4} & \mathrm{C}_{2} \mathrm{H}_{2} & \mathrm{C}_{2} \mathrm{H}_{4} & \mathrm{C}_{2} \mathrm{H}_{6} \\ \mathrm{C} & \mathrm{CH} & \mathrm{CH}_{2} & \mathrm{CH}_{3} \\ \mathrm{C}_{2} \mathrm{H} & \mathrm{C}_{2} \mathrm{H}_{3} & \mathrm{C}_{2} \mathrm{H}_{5} & \end{array}$

oxygenated hydrocarbons and fragments (up to $\mathrm{C}_{2}$ ):

$\begin{array}{lllll}\mathrm{CO} & \mathrm{CO}_{2} & & & \\ \mathrm{HCO} & \mathrm{CH}_{3} \mathrm{OH} & \mathrm{CH}_{2} \mathrm{OH} & \mathrm{CH}_{3} \mathrm{O} & \mathrm{CH}_{2} \mathrm{O} \\ \mathrm{CH}_{2} \mathrm{CO} & \mathrm{HCCO} & \mathrm{CH}_{3} \mathrm{CHO} & \mathrm{CH}_{3} \mathrm{CO} & \mathrm{HCCOH}\end{array}$

fluorine/hydrogen:

$\mathrm{F} \quad \mathrm{HF}$

hydrofluoro(mono)carbons and fragments:

$\begin{array}{llll}\mathrm{CF}_{4} & \mathrm{CHF}_{3} & \mathrm{CH}_{2} \mathrm{~F}_{2} & \mathrm{CH}_{3} \mathrm{~F} \\ \mathrm{CF}_{3} & \mathrm{CHF}_{2} & \mathrm{CH}_{2} \mathrm{~F} & \\ \mathrm{CF}_{2} & \mathrm{CHF} & \mathrm{CF} & \end{array}$

single-carbon-bond $\mathrm{HFCs}$ and fragments:
$\mathrm{CF}_{3} \mathrm{CF}_{3}$
$\mathrm{CHF}_{2} \mathrm{CF}_{3}$
$\mathrm{CH}_{2} \mathrm{FCF}_{3}$
$\mathrm{CH}_{3} \mathrm{CF}_{3}$
$\mathrm{CHF}_{2} \mathrm{CHF}_{2} \quad \mathrm{CH}_{2} \mathrm{FCHF}_{2} \quad \mathrm{CH}_{3} \mathrm{CHF}_{2}$
$\mathrm{CH}_{2} \mathrm{FCH}_{2} \mathrm{~F} \quad \mathrm{CH}_{3} \mathrm{CH}_{2} \mathrm{~F}$
$\mathrm{CF}_{3} \mathrm{CF}_{2}$
$\mathrm{CHF}_{2} \mathrm{CF}_{2}$
$\mathrm{CH}_{2} \mathrm{FCF}_{2}$
$\mathrm{CH}_{3} \mathrm{CF}_{2}$
$\mathrm{CF}_{3} \mathrm{CHF}$
$\mathrm{CHF}_{2} \mathrm{CHF}$
$\mathrm{CH}_{2} \mathrm{FCHF}$
$\mathrm{CH}_{3} \mathrm{CHF}$
$\mathrm{CF}_{3} \mathrm{CH}_{2}$
$\mathrm{CHF}_{2} \mathrm{CH}_{2} \quad \mathrm{CH}_{2} \mathrm{FCH}_{2}$

double-carbon-bond HFCs and fragments:
$\mathrm{CF}_{2} \mathrm{CF}_{2}$
$\mathrm{CF}_{2} \mathrm{CHF}$
$\mathrm{CF}_{2} \mathrm{CH}_{2}$
$\mathrm{CHFCHF}$
$\mathrm{CHFCH}_{2}$
$\mathrm{CF}_{2} \mathrm{CF}$
$\mathrm{CF}_{2} \mathrm{CH}$
$\mathrm{CHFCF}$
$\mathrm{CHFCH}$
$\mathrm{CH}_{2} \mathrm{CF}$

triple-carbon $\mathrm{HFCs}$ :
$\mathrm{CFCF}$
$\mathrm{CFCH}$

oxygenated hydrofluorocarbons and fragments (up to $\mathrm{C}_{2}$ ):
$\mathrm{CF}_{3} \mathrm{O}$
$\mathrm{CF}_{2} \mathrm{O}$
CFO
$\mathrm{CHFO}$
CHFCO
$\mathrm{CF}_{2} \mathrm{CO}$
FCCO 
effect of the temperature gradient on mass diffusion (i.e., the Soret effect) is included (TDIF). Up-wind differencing is used for the convective term (WDIF), and the flame is assumed to be anchored at the location where the temperature reaches $127^{\circ} \mathrm{C}$. The parameters GRAD and CURV control the development of the grid spacing, with small values of each restraining the maximum first and second derivatives in the species profiles that will be tolerated. The former is set at 0.3 and the latter at 0.4 . The absolute and relative tolerances placed on convergence of the Newton iteration are ATOL $=0.5 \times 10^{-9}$ to $1.0 \times 10^{-9}$, and RTOL $=0.5 \times 10^{-4}$ to $1.0 \times 10^{-4}$, respectively. The time steps (TIME and TIM2) range from $10^{-6}$ to $10^{-5} \mathrm{~s}$, with convergence tolerating a maximum difference (ATIM and RTIM) of $10^{-5} \mathrm{~s}$ between steps. Refer to Kee et al. (1985) for further explanation of these parameters.

The required number of grid points across the flame in a converged solution ranged between 60 for a stoichiometric $\mathrm{CH}_{4}$ /air flame to 160 for a $\mathrm{CH}_{2} \mathrm{~F}_{2}$ /air flame approaching its lean flammability limit. The numerical program as received from Sandia National Laboratory was designed to run on a work-station, but was modified in the current effort to be compatible with the NIST Convex C3820 vector machine. Depending upon the initial conditions in the problem and the accuracy of the first guess for the temperature profile, it took from $500 \mathrm{~s}$ to $30,000 \mathrm{~s}$ of CPU time to reach a converged solution.

Structure of the methane $\left(\mathrm{CH}_{4}\right) /$ air and R-32 $\left(\mathrm{CH}_{2} \mathrm{~F}_{2}\right) /$ air flames: Table VI lists the 83 different species that were considered in this study. Only the first thirty-two (nitrogen, oxygen, hydrogen, $\mathrm{C}_{1}$ - and $\mathrm{C}_{2}$-hydrocarbons and oxygenated hydrocarbons) are relevant for the $\mathrm{CH}_{4} /$ air flame. Figure 11 is a plot of the temperature and nine of these species as a function of distance through a stoichiometric $(\Phi=1.0)$ flame. The temperature (solid line in the upper graph) is initially $25^{\circ} \mathrm{C}$, it rises steeply within the first millimeter, and gets within $50{ }^{\circ} \mathrm{C}$ of its equilibrium value $\left(1850^{\circ} \mathrm{C}\right)$ at a location near $3 \mathrm{~mm}$. The methane and oxygen mole fractions are also plotted in the upper graph, with the fuel disappearing quickly and the oxygen leveling off to its equilibrium value. The mole fractions of major products $\left(\mathrm{H}_{2} \mathrm{O}\right.$ and $\left.\mathrm{CO}_{2}\right)$ increase accordingly. The level of the $\mathrm{CO}$ exceeds that of the $\mathrm{CO}_{2}$ in the region of the flame where the temperature is increasing most rapidly. Beyond $1 \mathrm{~mm}$, the $\mathrm{CO}$ is consumed and drops well below the $\mathrm{CO}_{2}$ mole fraction. Notice that the mole fractions of the product species are non-zero at the start of the flame. This results from diffusion counter to the flow due to the steep concentration gradients in the primary reaction zone.

The lower graph in Figure 11 shows the mole fraction of four intermediate species including one which is stable $\left(\mathrm{H}_{2}\right)$ and three unstable radicals $\left(\mathrm{OH}, \mathrm{HO}_{2}\right.$ and $\left.\mathrm{CH}_{2}\right)$. The hydrogen behaves similarly to the $\mathrm{CO}$ except that its peak value is diminished and it is spread more broadly due to the high mobility of the hydrogen molecule. The $\mathrm{OH}$ builds up quickly and decays slowly. The $\mathrm{O}$ and $\mathrm{H}$ atoms (not shown) behave qualitatively the same. The $\mathrm{CH}_{2}$ is representative of the other small hydrocarbon fragments (e.g., $\mathrm{CH}_{3}, \mathrm{CH}$ ), reaching a peak in the region where the temperature increase is maximum and then practically disappearing shortly beyond the $\mathrm{OH}$ maximum. $\mathrm{HO}_{2}$ behaves somewhat differently, increasing its value more quickly than the other radicals but then decaying to an equilibrium mole fraction more than three orders-of-magnitude below that of $\mathrm{OH}$. 


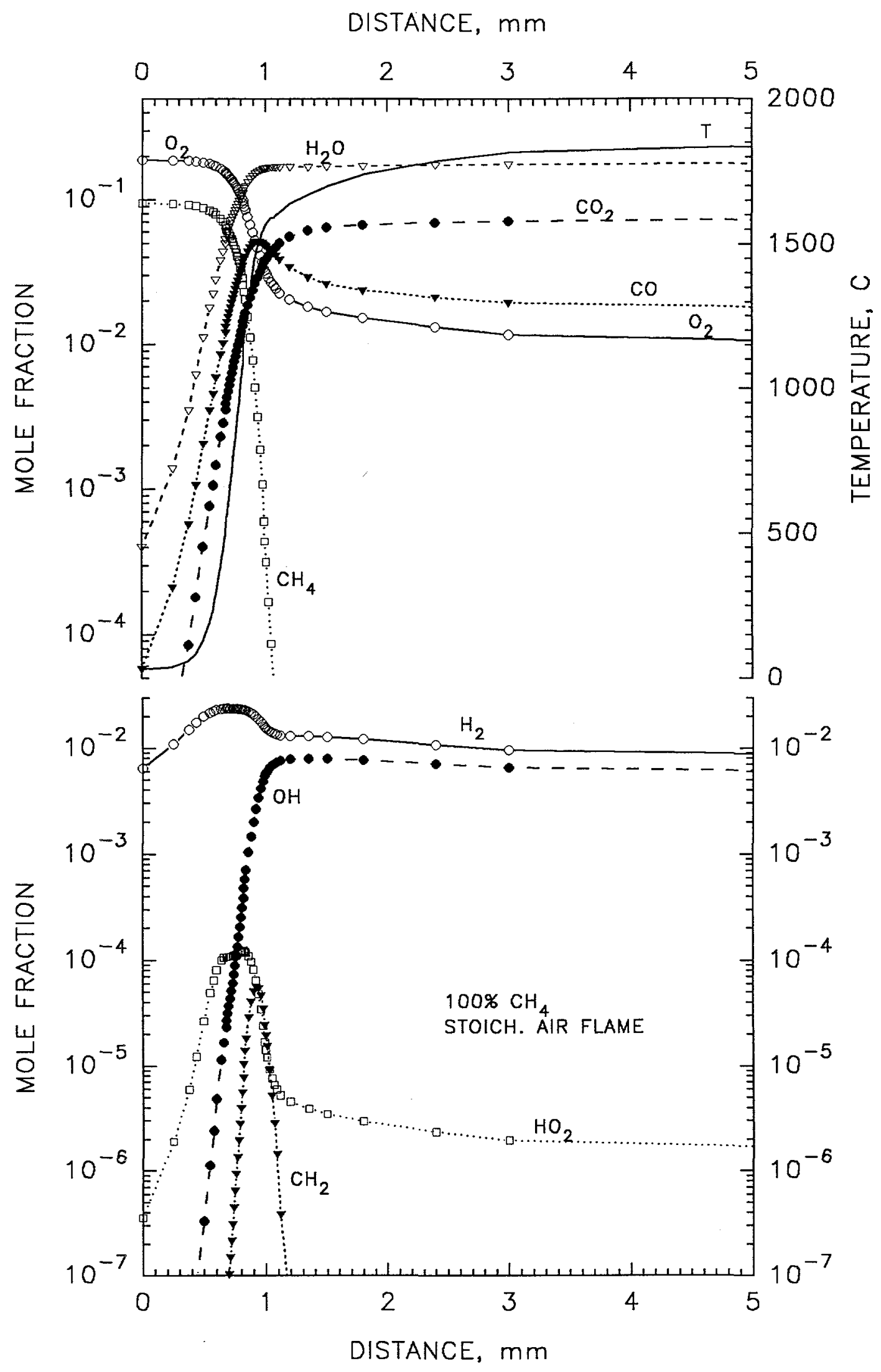

Figure 11: $\quad$ Structure of a stoichiometric methane $\left(\mathrm{CH}_{4}\right) /$ air flame. 
The structure of the stoichiometric $\mathrm{CH}_{2} \mathrm{~F}_{2}$ /air flame is, for comparison, shown in Figure 12. The temperature (the solid line in the upper graph) builds up more slowly but reaches a value almost as high as in the $\mathrm{CH}_{4}$ flame. The fuel drops quickly and the $\mathrm{O}_{2}$ also attains about the same final value as for $\mathrm{CH}_{4}$. The $\mathrm{CO}$ and $\mathrm{CO}_{2}$ mole fractions are a little higher in $\mathrm{CH}_{2} \mathrm{~F}_{2}$ combustion, but the $\mathrm{H}_{2} \mathrm{O}$ is two orders-of-magnitude lower. The main hydrogen-containing product is $\mathrm{HF}$, which approaches a mole fraction of 0.30 at equilibrium. The lower graph in Figure 12 shows the significant differences in the mole fractions of some of the minor constituents. The $\mathrm{H}_{2}$ is much less prevalent and the $\mathrm{OH}, \mathrm{CH}_{2}$, and $\mathrm{HO}_{2}$ radicals build up more slowly. The second new species in abundance is $\mathrm{CF}_{2} \mathrm{O}$, carbonyl fluoride, which reaches a peak in excess of $2 \%$ of the mixture.

The horizontal distance through the flame can be transformed to a cumulative time scale by dividing each increment in position by the local computed velocity. The upper graph of Figure 13 compares the temperature and $\mathrm{OH}$ mole fraction time histories for the $\mathrm{CH}_{4}$ and $\mathrm{CH}_{2} \mathrm{~F}_{2}$ flames. On this basis the large differences in flame structure are accentuated. Even though the final temperatures are similar in magnitude, it takes the $\mathrm{CH}_{2} \mathrm{~F}_{2}$ flame more than ten times as long to reach an equivalent temperature. The build up in $\mathrm{OH}$ likewise takes an order of magnitude longer and is a little more than one tenth as great for the $\mathrm{CH}_{2} \mathrm{~F}_{2}$ flame. The disparate behavior of the two flames is further demonstrated in the lower graph of Figure 13. Here, the derivative of the temperature as a function of time is plotted. The same factor of ten exists in magnitude and time.

Figure 14 shows how the strength of a stoichiometric flame is diminished as the mole fraction of $\mathrm{CH}_{2} \mathrm{~F}_{2}$ in the fuel is increased from 0 to 1.0 . The final temperature varies only slightly, whereas the $\mathrm{OH}$ and $\mathrm{H}_{2}$ drop monotonically to less than $20 \%$ of their value in the pure methane flame (upper graph). The effect of the $\mathrm{CH}_{2} \mathrm{~F}_{2}$ level on flame speed is shown in the lower graph of Figure 14. The speed of the stoichiometric pure $\mathrm{CH}_{2} \mathrm{~F}_{2}$ flame is calculated to be less than $20 \%$ of the pure methane flame. A drop in flame speed with increasing $\mathrm{CH}_{2} \mathrm{~F}_{2}$ mole fraction was observed experimentally by Linteris and Truett (1996) in their premixed laminar co-flowing flame. Also plotted in the graph is the flame speed divided by the flame thickness. The distance between the start of the flame $(\mathrm{x}=0 \mathrm{~mm})$ and the location of the maximum concentration of $\mathrm{OH}$ was chosen as representative of the flame thickness (refer to Figure 13), because the peak $\mathrm{OH}$ occurs close to the peak temperature gradient, and can be identified in an unambiguous way.

The impact of equivalence ratio on the structure of both the $\mathrm{CH}_{4} /$ and $\mathrm{CH}_{2} \mathrm{~F}_{2}$ /air flames has been examined using the premixed flame code. Figure 15 is a plot of the final temperature, peak $\mathrm{OH}$ mole fraction, flame speed, and speed-to-thickness ratio as a function of $\Phi$, where

$$
\Phi=4.76(2-x)\left(\frac{\mathrm{X}_{\mathrm{CH} 2 \mathrm{~F} 2}+\mathrm{X}_{\mathrm{CH} 4}}{\mathrm{X}_{\text {air }}}\right)
$$

and $x$ is the fraction of $\mathrm{CH}_{2} \mathrm{~F}_{2}$ in the fuel mixture. In the upper graph, the temperature of both flames increases continuously as $\Phi$ approaches unity. Note that the final temperature in the $\mathrm{CH}_{2} \mathrm{~F}_{2}$ flame exceeds that of the methane flame when the equivalence ratio is leaner than about 0.86. The peak $\mathrm{OH}$ concentration in the methane flame behaves in the same manner as the 


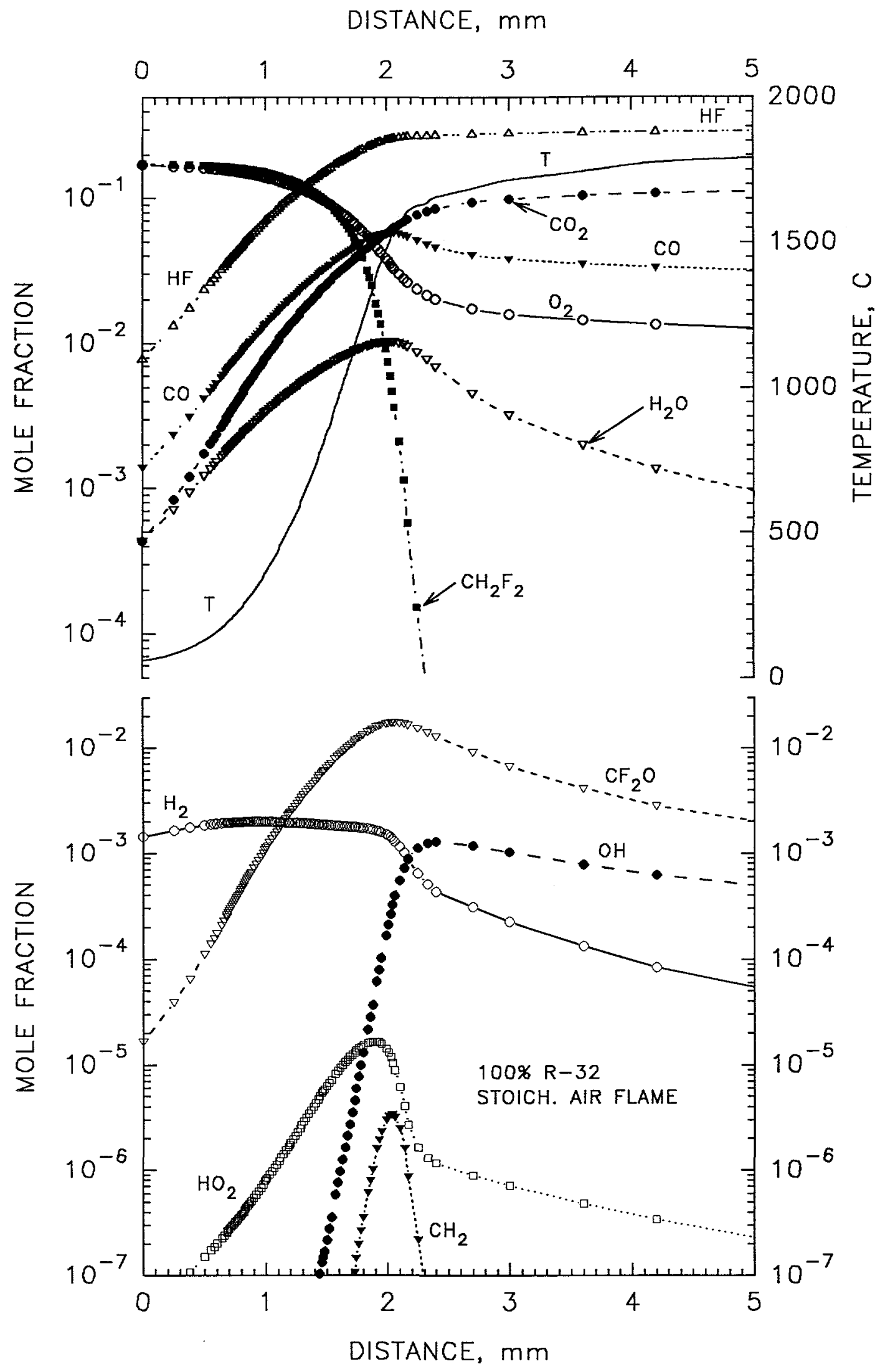

Figure 12: $\quad$ Structure of stoichiometric R-32 $\left(\mathrm{CH}_{2} \mathrm{~F}_{2}\right) /$ air flame. 
TIME, ms

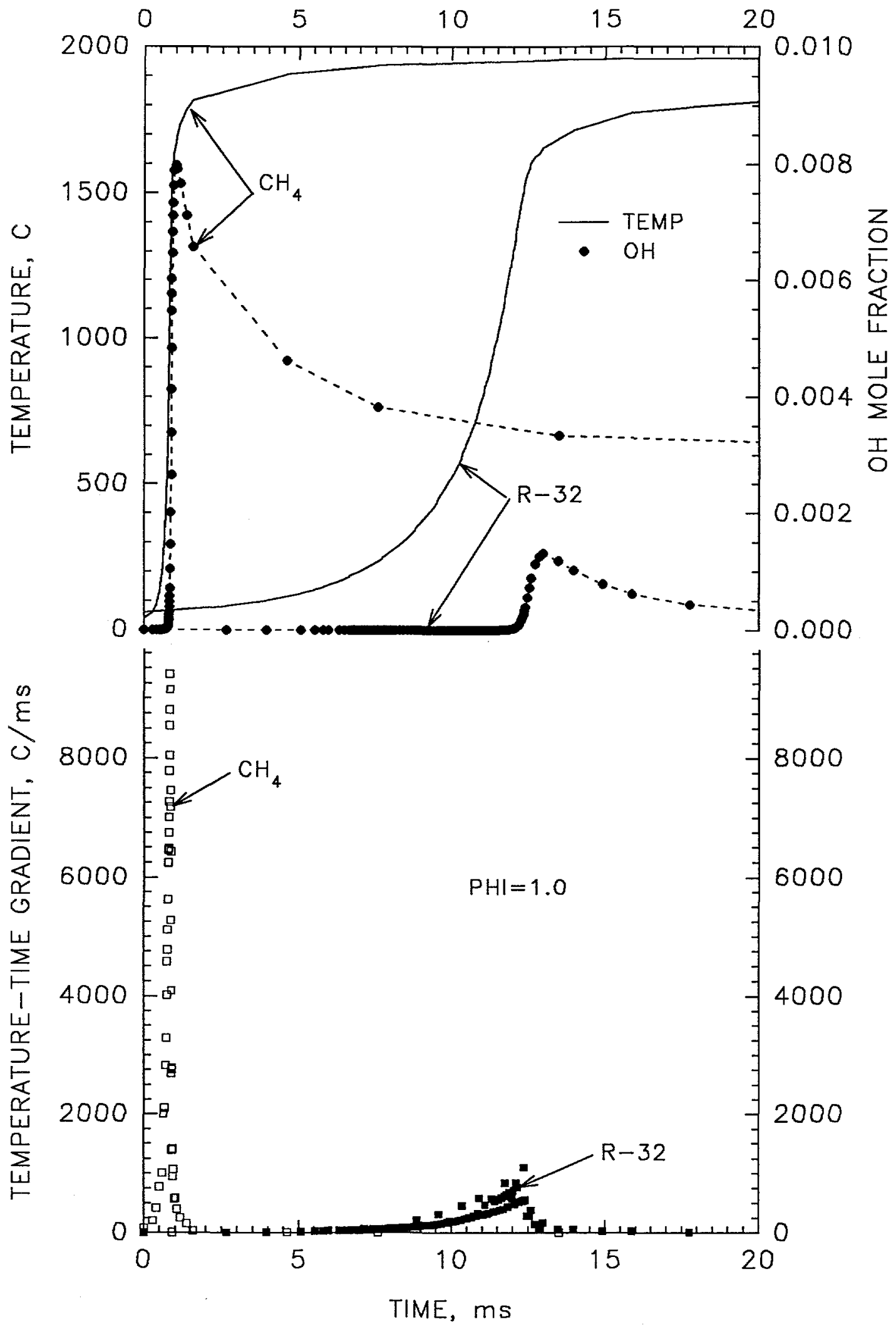

Figure 13: (a) Temperature and $\mathrm{OH}$ levels as a function of time in stoichiometric methane $\left(\mathrm{CH}_{4}\right)$ and $\mathrm{R}-32\left(\mathrm{CH}_{2} \mathrm{~F}_{2}\right)$ flames. (b) Derivatives of temperature curves in (a). 


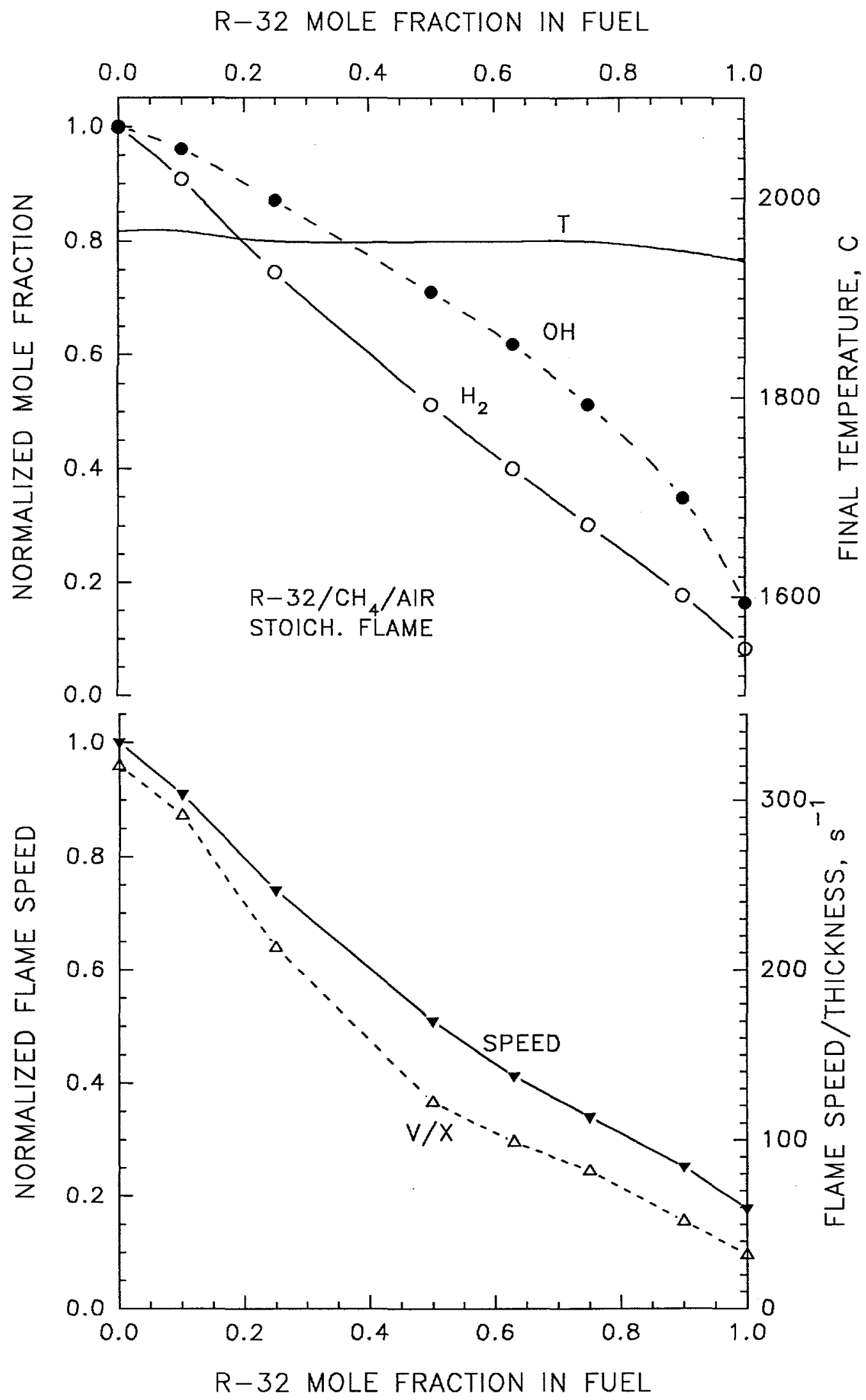

Figure 14: Flame parameters as a function of the amount of $\mathrm{R}-32\left(\mathrm{CH}_{2} \mathrm{~F}_{2}\right)$ in methane $\left(\mathrm{CH}_{4}\right)$ mixture, $\Phi=1.0$. 
EQUIVALENCE RATIO

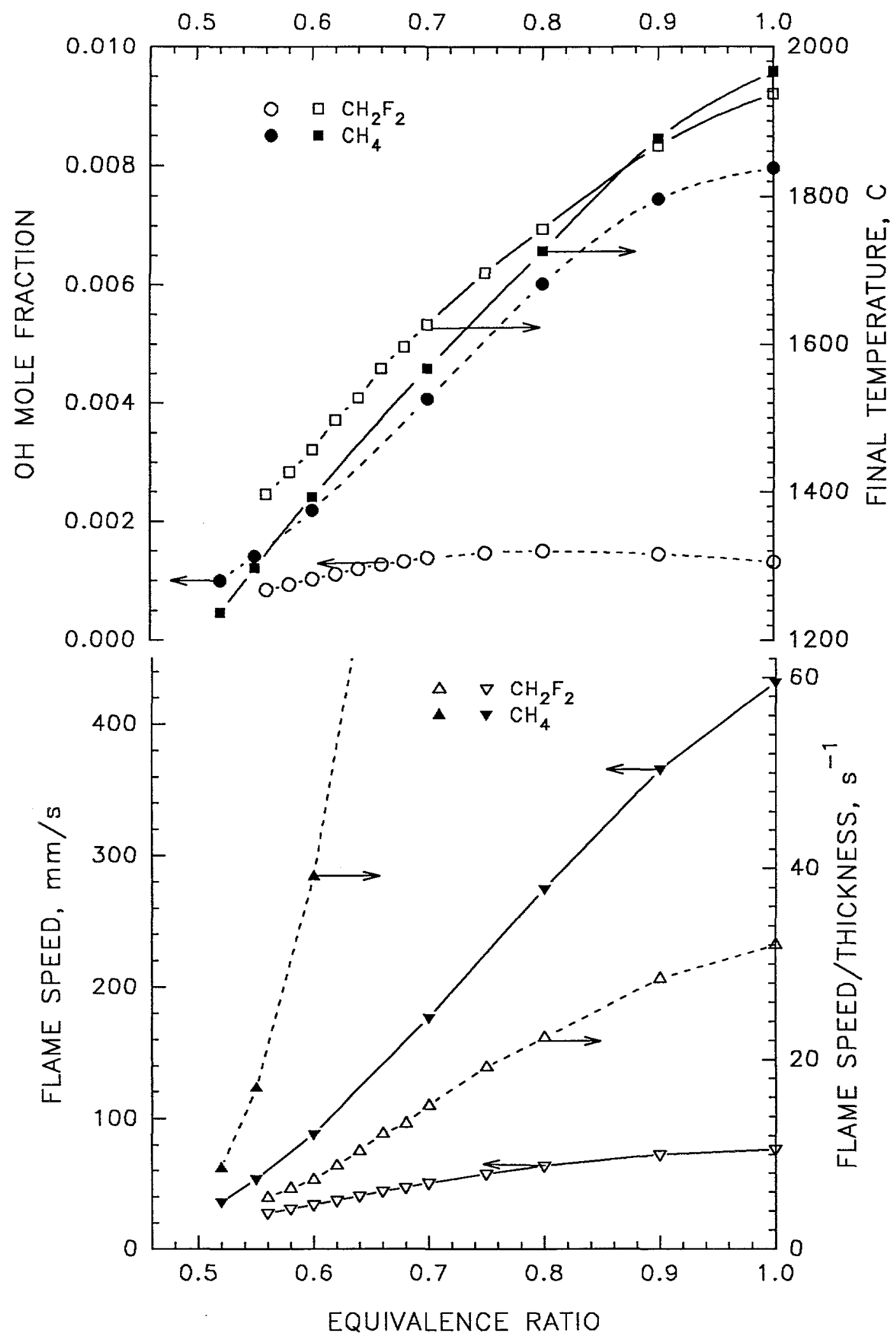

Figure 15: Effect of fuel/air equivalence ratio on pure $\mathrm{CH}_{4} /$ air and $\mathrm{R}-32\left(\mathrm{CH}_{2} \mathrm{~F}_{2}\right) /$ air flames. 
temperature. However, for $\mathrm{CH}_{2} \mathrm{~F}_{2}$, initially the $\mathrm{OH}$ increases as the flame becomes leaner, and is almost one half the $\mathrm{OH}$ mole fraction in the methane flame when $\Phi=0.60$.

The lower graph in Figure 15 compares the flame speeds and speed-to-thickness ratios as a function of $\Phi$. For $\mathrm{CH}_{4}, \Phi=0.52$ was the leanest flame for which a converged solution could be attained. The flame speed at this equivalence ratio is less than $40 \mathrm{~mm} / \mathrm{s}$. Numerical solutions for the $\mathrm{CH}_{2} \mathrm{~F}_{2}$ flame were obtained down to an equivalence ratio of 0.56 , with the flame speed calculated to be above $30 \mathrm{~mm} / \mathrm{s}$ at the lean extreme. The speed-to-thickness ratio in the $\mathrm{CH}_{4} /$ air flame decreases steeply with decreasing equivalence ratio, dropping below $10 \mathrm{~s}^{-1}$ when $\Phi=0.52$. The speed-to-thickness ratio for the $\mathrm{CH}_{2} \mathrm{~F}_{2}$ flame drops much less steeply as the equivalence ratio is reduced, but more steeply than the absolute value of the $\mathrm{CH}_{2} \mathrm{~F}_{2}$ flame speed.

If the flame-speed-to-thickness ratio for $\mathrm{CH}_{4}$ is extrapolated to zero, the horizontal intercept is $\Phi=0.49$, which corresponds to published values of the lean flammability limit of methane (refer to Table III). This suggests that the theoretical flame-speed-to-thickness ratio may be directly related to the extinction strain rate measured in a premixed opposed-flow flame. When one extrapolates the speed-to-thickness ratio to zero for the $\mathrm{CH}_{2} \mathrm{~F}_{2}$ /air flame, however, the lean flammability limit is found to be below that of the methane/air flame. This is counter to what has been found experimentally (Table IV).

R-125/R-32 and R-134a/R-32 mixtures: Mixtures of $\mathrm{C}_{2} \mathrm{HF}_{5}(\mathrm{R}-125)$ and $\mathrm{CH}_{2} \mathrm{~F}_{2}(\mathrm{R}-32)$ were studied experimentally in Phase I of this project (Womeldorf et al., 1995). The chemistry of two-carbon hydrofluorocarbon oxidation is included in the modified CHEMKIN kinetics package (Burgess et al., 1995), which allows the flame speed of $\mathrm{C}_{2} \mathrm{HF}_{5} / \mathrm{CH}_{2} \mathrm{~F}_{2} /$ air mixtures to be estimated. The top graph in Figure 16 shows the results of these calculations. The flame temperature, velocity, and $\mathrm{OH}$ concentration for the stoichiometric $\mathrm{CH}_{2} \mathrm{~F}_{2}$ /air flame are used to normalize the parameters as the mole fraction of $\mathrm{C}_{2} \mathrm{HF}_{5}$ in the fuel mixture is increased from 0 to 0.14 . The overall equivalence ratio is kept at 1.0 based upon the following equation for complete combustion:

$$
x \mathrm{C}_{2} \mathrm{HF}_{5}+(1-x) \mathrm{CH}_{2} \mathrm{~F}_{2}+\left(\mathrm{O}_{2}+3.76 \mathrm{~N}_{2}\right)=(2-x) \mathrm{HF}+x \mathrm{COF}_{2}+\frac{x}{2} \mathrm{CF}_{4}+\left(1-\frac{x}{2}\right) \mathrm{CO}_{2}+3.76 \mathrm{~N}_{2}
$$

The temperature drops only slightly as the $\mathrm{C}_{2} \mathrm{HF}_{5}$ fraction is increased. However, the $\mathrm{OH}$ decreases dramatically, dropping to about $5 \%$ of the pure $\mathrm{CH}_{2} \mathrm{~F}_{2}$ flame when the $\mathrm{C}_{2} \mathrm{HF}_{5}$ fraction is 0.14 . The flame speed at this $\mathrm{C}_{2} \mathrm{HF}_{5}$ level is less than $40 \%$ of the pure $\mathrm{CH}_{2} \mathrm{~F}_{2}$ flame, while the flame-speed-to-thickness ratio is only $6 \mathrm{~s}^{-1}$. If the $\mathrm{v} / \mathrm{x}$ curve were extrapolated until it intersected the horizontal axis, the fraction of $\mathrm{C}_{2} \mathrm{HF}_{5}$ in the fuel would be about 0.19 . This compares favorably to a critical flammability ratio of 0.185 measured in the Phase I counter flow flame (Womeldorf et al., 1995).

Also plotted in Figure 16 (see lower graph) are the above flame parameters for $\mathrm{C}_{2} \mathrm{H}_{2} \mathrm{~F}_{4} / \mathrm{CH}_{2} \mathrm{~F}_{2} /$ air $(\mathrm{R}-134 \mathrm{a} / \mathrm{R}-32 / \mathrm{air})$ mixtures. The general shapes of the curves are similar to those found in the $\mathrm{C}_{2} \mathrm{HF}_{5} / \mathrm{CH}_{2} \mathrm{~F}_{2}$ system, except that the horizontal scale has been compressed. The additional hydrogen atom in the $\mathrm{C}_{2} \mathrm{H}_{2} \mathrm{~F}_{4}$ molecule increases the flammability of the mixture 
(a) R-125 MOLE FRACTION IN FUEL

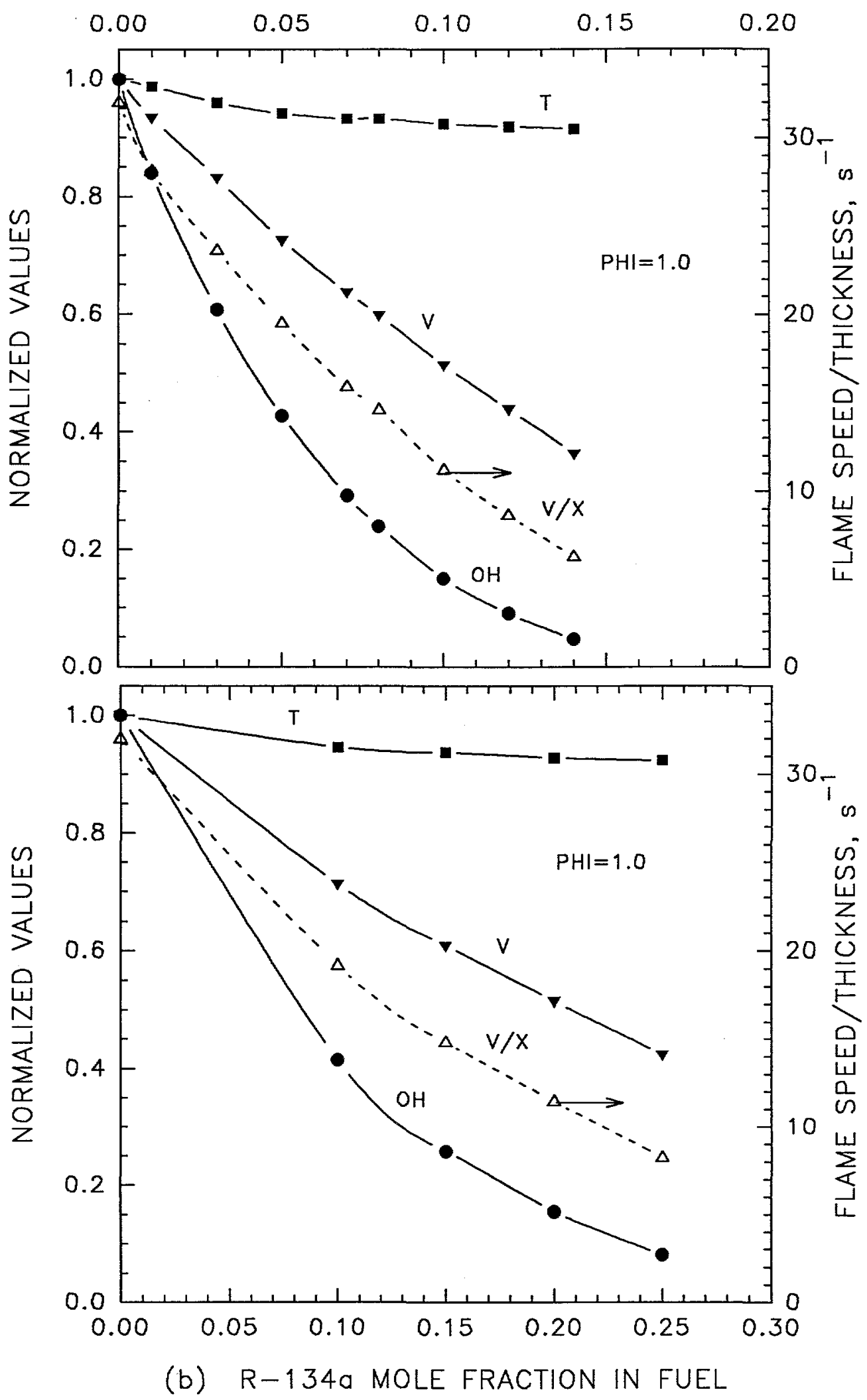

Figure 16: Flame parameters as a function of the amount of (a) R-125 $\left(\mathrm{C}_{2} \mathrm{HF}_{5}\right)$ and (b) R-134a $\left(\mathrm{C}_{2} \mathrm{H}_{2} \mathrm{~F}_{4}\right)$ in an R-32 $\left(\mathrm{CH}_{2} \mathrm{~F}_{2}\right)$ mixture, $\Phi=1.0$. 
somewhat, but the extrapolation of $\mathrm{v} / \mathrm{x}$ to zero suggests that mixtures containing more than about $38 \%$ by volume $\mathrm{C}_{2} \mathrm{H}_{2} \mathrm{~F}_{4}$ will not sustain a flame.

Impact of relative humidity and initial temperature: All of the flame calculations presented so far have taken the air to be dry (i.e., the relative humidity is $0 \%$ at $25{ }^{\circ} \mathrm{C}$ ). Figure 17 demonstrates what happens when moisture is added to the air. The saturation pressure of water at $25^{\circ} \mathrm{C}$ is $3.17 \mathrm{kPa}$. This means that when the air pressure is atmospheric $(101 \mathrm{kPa})$ the mole fraction of water at $100 \%$ relative humidity is 0.031 . The actual mole fraction of water used in the calculations is reduced by a factor equal to the mole fraction of air in the dry air plus fuel mixture. The upper graph in Figure 17 is for a stoichiometric $10 \% \mathrm{C}_{2} \mathrm{HF}_{5} / 90 \% \mathrm{CH}_{2} \mathrm{~F}_{2} /$ air flame, and the lower graph is for a lean $(\Phi=0.70) \mathrm{CH}_{2} \mathrm{~F}_{2}$ /air flame. The final temperature is not much affected by the moisture, but the peak $\mathrm{OH}$ mole fraction increases almost four-fold in the $\mathrm{C}_{2} \mathrm{HF}_{5} / \mathrm{CH}_{2} \mathrm{~F}_{2}$ flame with increasing humidity. Interestingly, the speed-to-thickness ratio and normalized flame speed are enhanced with added moisture in the $\mathrm{C}_{2} \mathrm{HF}_{5} / \mathrm{CH}_{2} \mathrm{~F}_{2}$ /air flame, while they are reduced in the lean $\mathrm{CH}_{2} \mathrm{~F}_{2}$ /air flame. This seeming inconsistency can be explained by comparing the $\mathrm{H}$-atom to $\mathrm{F}$-atom ratio in the two flames. The pure $\mathrm{CH}_{2} \mathrm{~F}_{2}$ /air flame has an $\mathrm{H} / \mathrm{F}$ ratio of $1: 1$ independent of the stoichiometry. This means that there is no excess of fluorine atoms to tie up the H-atoms critical to the flame propagation. When $\mathrm{C}_{2} \mathrm{HF}_{5}$ is added to the fuel, the $\mathrm{H} / \mathrm{F}$ ratio drops below $1: 1\left(0.826\right.$ for the $10 \% \mathrm{C}_{2} \mathrm{HF}_{5}$ flame). Hence, the water brings the $\mathrm{OH}$ and $\mathrm{H}$ levels above the threshold vital to maintaining the combustion reaction.

The final parameter investigated was the initial temperature. Figure 18 shows how the velocity, $\mathrm{OH}$ level and final temperature are impacted as the initial mixture temperature is increased. The system is a stoichiometric $10 \% \mathrm{C}_{2} \mathrm{HF}_{5} / 90 \% \mathrm{CH}_{2} \mathrm{~F}_{2}$ /dry air flame, with the values at $25{ }^{\circ} \mathrm{C}$ used to normalize the parameters. An increase in initial temperature of $40{ }^{\circ} \mathrm{C}$ (to $65{ }^{\circ} \mathrm{C}$ ) increases the final temperature by $20^{\circ} \mathrm{C}$, which is imperceptible when normalized by the final condition. There is a noticeable positive effect on the normalized $\mathrm{OH}$ mole fraction. The velocity of the flame increases by about $25 \%$, but the speed-to-thickness ratio is enhanced only slightly. By comparing the impact of the temperature change on the value of $\mathrm{v} / \mathrm{x}$ to the impact of changing the mole fraction of $\mathrm{C}_{2} \mathrm{HF}_{5}$, one can estimate that an increase in initial mixture temperature of $10{ }^{\circ} \mathrm{C}$ would produce an increase in the critical flammability ratio of approximately $0.5 \%$ for this particular flame system.

Comparison between experimental opposed-flow and theoretical one-dimensional flames: The experimental flames in the current study are established between counter-flowing jets at various equivalence ratios and strain rates. Losses due to conduction and radiation are not measured but can be estimated using the analyses of Hertzberg $(1976,1980,1982,1984)$. He showed that the minimum flame speed required of a mixture to overcome conduction losses is $\mathrm{v}_{\text {cond }} \approx \alpha / l_{c}$, where $\alpha$ is the average thermal diffusivity through the flame $\left(1.6 \times 10^{-6} \mathrm{~m}^{2} / \mathrm{s}\right.$ for air at $\left.700{ }^{\circ} \mathrm{C}\right)$ and $l_{c}$ is the conduction length scale. The heat loss due to radiation leads to a limiting flame speed ( $\left.\mathrm{v}_{\mathrm{rad}}\right)$ directly proportional to the optical thickness $\left(\mathrm{k}_{\mathrm{p}}\right)$, the radiation length scale $\left(l_{r}\right)$, and the cube of the flame temperature $\left(\mathrm{T}_{\mathrm{f}}\right)$. The change in flame volume due to stretch can be expressed in terms of the velocity. The limit velocity due to flame stretch is approximately equal to $(\alpha K)^{1 / 2}$, so for the above value of $\alpha, v_{\text {strain }} \approx 0.0126 K^{1 / 2}$. 


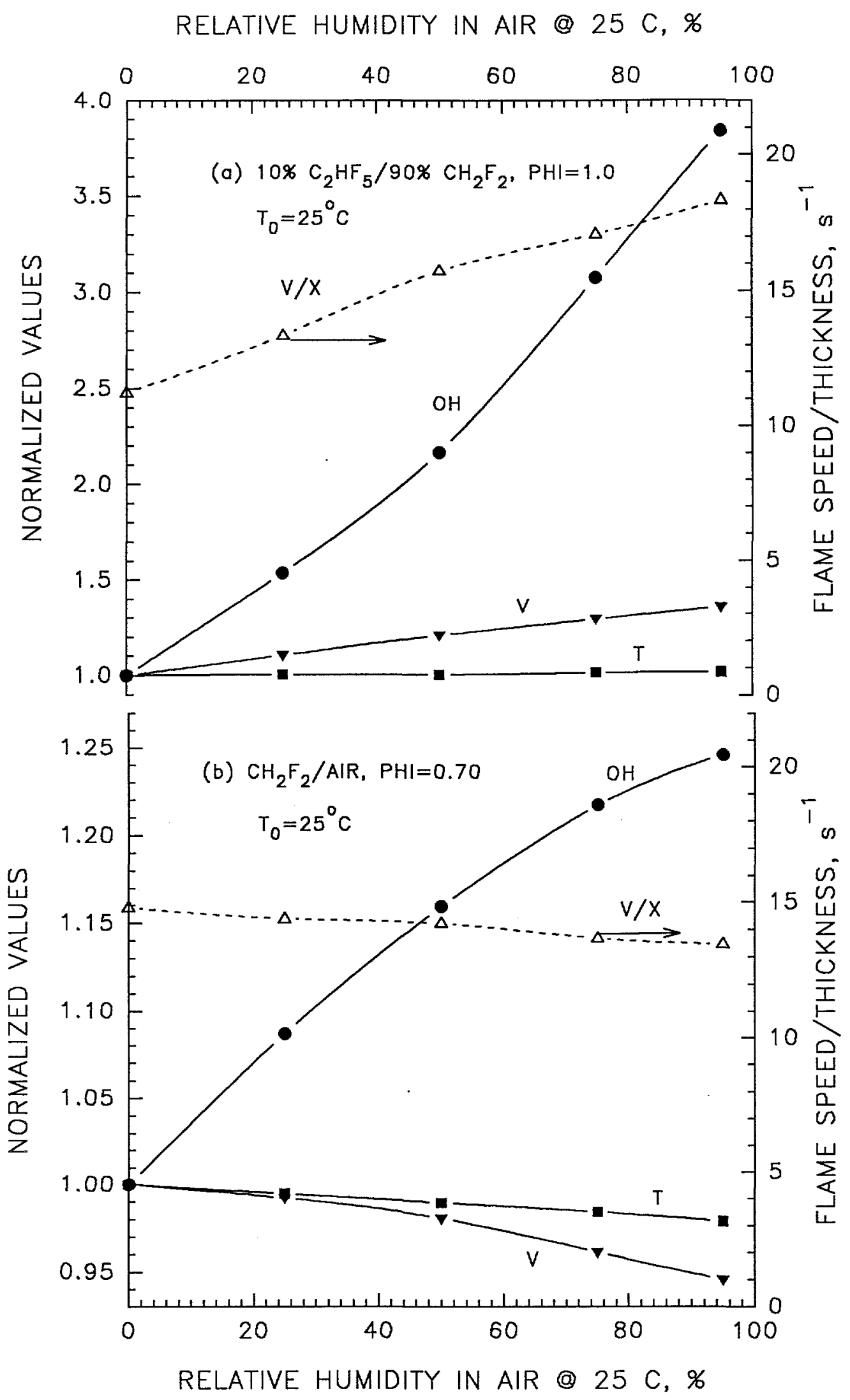

Figure 17: Effect of relative humidity on (a) $10 \% \mathrm{R}-125 / 90 \% \mathrm{R}-32 / \mathrm{air}(\Phi=1.0)$ and (b) R-32/air $(\Phi=0.7)$ flame. 


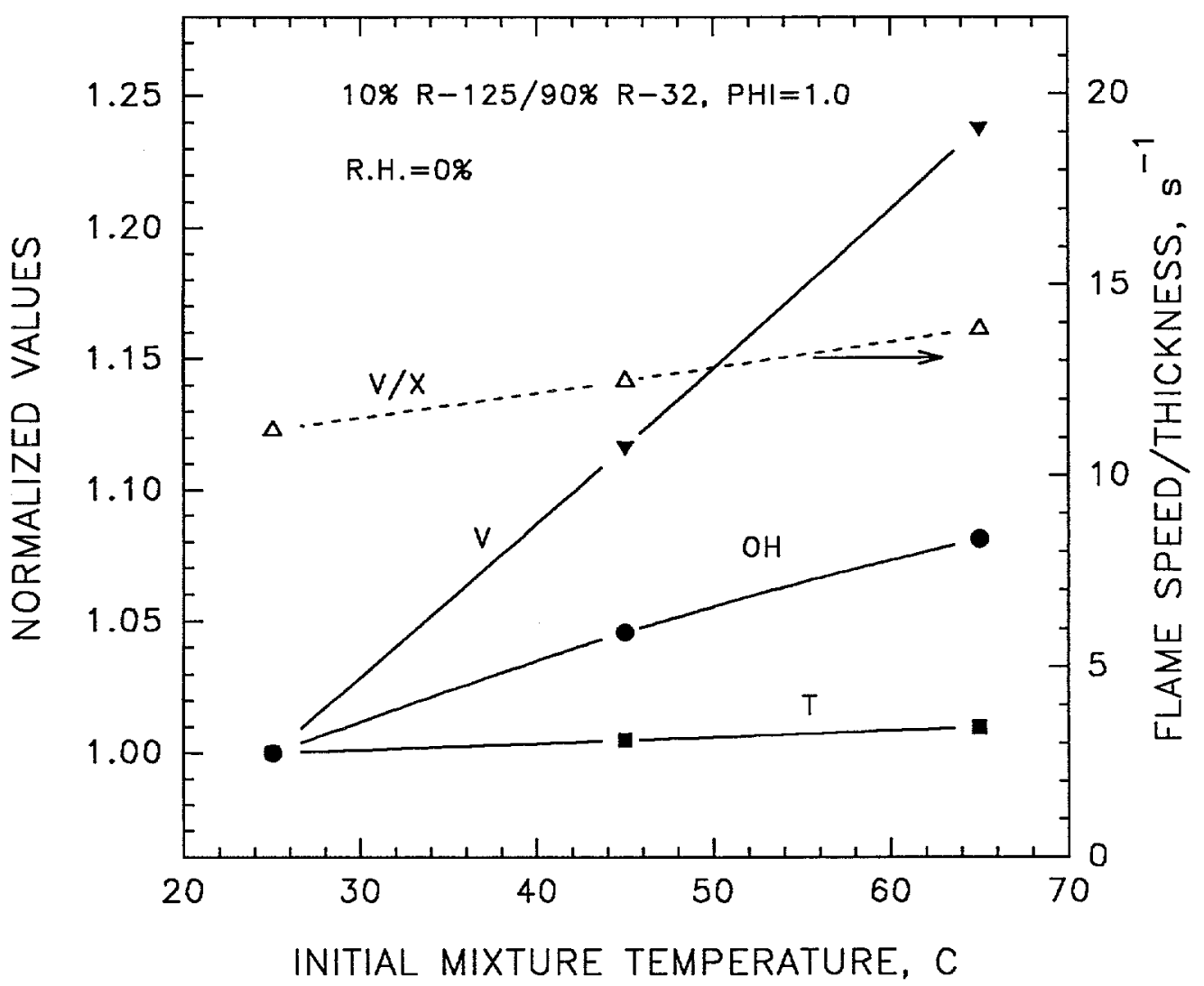

Figure 18: Effect of initial temperature on $10 \%$ R-125/90 \% R-32 air flame (R.H. $=0$, $\Phi=1.0$ ). 
Table VII: $\quad$ Calculated and experimental properties of $\mathrm{CH}_{4} /$ air and $\mathrm{CH}_{2} \mathrm{~F}_{2} /$ air flames

\begin{tabular}{|c|c|c|c|c|c|c|}
\hline $\begin{array}{c}\text { Fuel/Air } \\
\text { Equivalence } \\
\text { Ratio } \\
\Phi\end{array}$ & $\begin{array}{c}\text { Burnt gas } \\
\text { Temperature } \\
\mathrm{T}_{\mathrm{f}} \\
\left({ }^{\circ} \mathrm{C}\right)\end{array}$ & $\begin{array}{c}\text { a Burnt gas } \\
\text { density } \\
\rho_{\mathrm{f}} \\
\left(\mathrm{kg} / \mathrm{m}^{3}\right) \\
\end{array}$ & $\begin{array}{c}{ }^{\text {a Burnt gas }} \\
\text { specific heat } \\
c_{\mathrm{p}} \\
(\mathrm{kJ} / \mathrm{kg} / \mathrm{K})\end{array}$ & $\begin{array}{c}{ }^{\mathrm{b}_{\text {Burnt gas }}} \\
\text { absorption } \\
\text { coefficient, } \mathrm{k}_{\mathrm{p}} \\
\left(\mathrm{m}^{-1}\right)\end{array}$ & $\begin{array}{c}\text { a Average } \\
\text { thermal } \\
\text { diffusivity } \\
\left(\mathrm{m}^{2} / \mathrm{s}\right)\end{array}$ & $\begin{array}{c}\text { Experimental } \\
\text { extinction strain } \\
\text { rate } \\
K_{\exp }\left(\mathrm{s}^{-1}\right) \\
\end{array}$ \\
\hline \multicolumn{7}{|l|}{$\mathrm{CH}_{4}$} \\
\hline 0.8 & 1727 & 0.176 & 1275 & 0.60 & $2.06 \times 10^{-4}$ & - \\
\hline 0.7 & 1567 & 0.191 & 1260 & 0.67 & $1.84 \times 10^{-4}$ & 210 \\
\hline 0.6 & 1393 & 0.212 & 1220 & 0.75 & $1.62 \times 10^{-4}$ & 85 \\
\hline 0.52 & 1237 & 0.234 & 1190 & 0.84 & $1.43 \times 10^{-4}$ & 40 \\
\hline \multicolumn{7}{|l|}{$\mathrm{CH}_{2} \mathrm{~F}_{2}$} \\
\hline 1.0 & 1928 & 0.160 & 1292 & 0.66 & $2.33 \times 10^{-4}$ & 70 \\
\hline 0.9 & 1812 & 0.169 & 1280 & 0.74 & $2.17 \times 10^{-4}$ & 39 \\
\hline 0.8 & 1645 & 0.184 & 1270 & 0.84 & $1.95 \times 10^{-4}$ & 7.5 \\
\hline 0.7 & 1464 & 0.203 & 1230 & 0.97 & $1.71 \times 10^{-4}$ & 0 \\
\hline 0.6 & 1277 & 0.228 & 1190 & 1.12 & $1.48 \times 10^{-4}$ & 0 \\
\hline
\end{tabular}

a Interpolated based upon tabulated properties of air.

${ }^{b}$ Calculated using RADCAL (Grosshandler, 1992).

Table VII summarizes the properties of the $\mathrm{CH}_{4}$ and $\mathrm{CH}_{2} \mathrm{~F}_{2}$ flames based upon equilibrium calculations and physical data drawn from the literature. The conduction and radiation scales are of the order of the diameter of the burner $(12 \mathrm{~mm}$, in the current work). The strain rate is the velocity gradient in the radial direction, which can be estimated from the solution for an inviscid axisymmetric jet impinging on a flat plate (Landau and Lifshitz, 1986): $K=\mathrm{v}_{\text {ave }} / \mathrm{H}$, where $\mathrm{v}_{\text {ave }}$ is the average inlet velocity and $\mathrm{H}$ is the nozzle spacing, which, in this case is equal to the nozzle diameter. The last column in the table is the extinction strain rate, determined from the experiments described earlier (see Figures 8 and 9).

The estimated minimum laminar flame speeds at the extinction conditions are shown in Table VIII, with the contributions necessary to overcome the conductive and radiative losses and the stretched flame conditions listed separately. The last column is the flame speed based upon the CHEMKIN simulation. Relative to the experimentally derived flame speed, the chemical kinetics code under-predicts the estimated laminar flame speed for $\mathrm{CH}_{2} \mathrm{~F}_{2}$ mixtures close to stoichiometric, and over-predicts the speed needed to sustain a flame under the leanest conditions. The estimated minimum laminar flame speed of $\mathrm{CH}_{4}$ is high by 40 or $50 \mathrm{~mm} / \mathrm{s}$ for all equivalence ratios. Using the $30 \mathrm{~mm} / \mathrm{s}$ limiting speed suggested by Hertzberg (1984), the lean flammability limit for $\mathrm{CH}_{2} \mathrm{~F}_{2}$ can be estimated to occur for an equivalence ratio around 0.60 , while for $\mathrm{CH}_{4}$ the limiting value (by extrapolation) would lie near 0.46 .

While the opposed-flow flame is ostensibly stationary and flat, buoyancy can distort the flame when the imposed strain (or inlet velocity) is too small. The limiting conditions can be estimated by treating the flame as a disc shaped balloon which is maintained equidistant between the jet 
outlets by the momentum of the matched incoming reactant flows. From Bernoulli's equation, the force of the inlet stream on the flame disc is equal to $\left(\rho_{\mathrm{o}} \mathrm{v}_{\mathrm{ave}} \mathrm{e}^{2 / 2}\right)\left(\pi \mathrm{D}^{2 / 4}\right)$. The buoyant force acting to move the flame disc counter to the gravitational field is $g\left(\rho_{\mathrm{o}}-\rho_{f}\right)\left(l \pi \mathrm{D}^{2 / 4}\right)$, where $l$ is the thickness of the flame disc. Recognizing that the density is inversely proportional to the temperature, the ratio of the force due to momentum and the force due to buoyancy can be written as

$$
\frac{F_{\text {mom }}}{F_{\text {buoy }}}=\frac{T_{f}}{T_{o}}\left(\frac{v_{\text {ave }}^{2}}{2 g l\left(T_{f} / T_{o}-1\right)}\right)
$$

The temperature ratio is about 6 , and the disc thickness is of the order of half the nozzle spacing, or $6 \mathrm{~mm}$. Setting the force ratio equal to one leads to a minimum inlet velocity of $0.32 \mathrm{~m} / \mathrm{s}$. In terms of the global strain rate, the limiting condition is

$$
K_{\min }=\sqrt{\frac{2 g}{l}\left(1-T_{o} / T_{f}\right)}
$$

This implies that for strain rates below about $27 \mathrm{~s}^{-1}$ the instabilities in the flame will increase operational difficulties and increase the uncertainties of the experimental results.

Table VIII: $\quad$ Minimum laminar flame speeds $(\mathrm{mm} / \mathrm{s})$ to overcome losses in $\mathrm{CH}_{4} /$ air and $\mathrm{CH}_{2} \mathrm{~F}_{2}$ mixtures

\begin{tabular}{c|c|c|c|c|c}
\hline $\begin{array}{c}\text { Fuel/ } \\
\text { Equivalence } \\
\text { Ratio, } \Phi\end{array}$ & $\begin{array}{c}\mathrm{v}_{\text {cond }} \boldsymbol{\alpha / l _ { c }} \\
\mathrm{CH}_{4}\end{array}$ & $\begin{array}{c}\mathrm{v}_{\mathrm{rad}}= \\
\mathrm{k}_{\mathrm{p}} l_{r} \sigma \mathrm{T}_{\mathbf{f}}^{3} \\
\mathrm{c}_{\mathrm{p}} \rho_{\mathrm{f}}\end{array}$ & $\begin{array}{c}\mathrm{v}_{\text {strain }}= \\
(\alpha K)^{1 / 2}\end{array}$ & $\begin{array}{c}\mathrm{v}_{\mathbf{o}}= \\
\mathrm{v}_{\text {cond }}+\mathrm{v}_{\text {rad }} \\
+\mathrm{v}_{\text {strain }}\end{array}$ & $\begin{array}{c}\mathrm{v}_{\mathbf{o}} \text { from } \\
\text { CHEMKIN }\end{array}$ \\
\hline 0.8 & 17.2 & 14.6 & - & - & 275 \\
0.7 & 15.3 & 11.8 & 196 & 223 & 177 \\
0.6 & 13.5 & 9.1 & 117 & 140 & 88.2 \\
0.52 & 11.9 & 7.1 & 75.6 & 94.6 & 36.0 \\
\hline $\mathrm{CH}_{2} \mathrm{~F}_{2}$ & & & & & \\
\hline 1.0 & 19.4 & 23.2 & 128 & 171 & 76.7 \\
0.9 & 18.1 & 21.1 & 92.0 & 131 & 72.6 \\
0.8 & 16.2 & 17.2 & 38.2 & 71.6 & 63.6 \\
0.7 & 14.2 & 13.8 & 0 & 28.0 & 50.3 \\
0.6 & 12.3 & 10.4 & 0 & 22.7 & 33.9 \\
\hline
\end{tabular}




\section{Conclusions}

Major findings: This report documents the completion of Phase II of the Lean Flammability Project. The opposed-flow burner has been redesigned to yield a uniform velocity profile at the nozzle exit. The flow control system has been modified to improve the accuracy and precision of the experiments, and a data analysis technique has been developed to provide the maximum information regarding uncertainty, systematic uncertainty factors, and the accuracy of the true lean flammability limit. The flammability limits measured, summarized in Table IX, are consistent with published values. The impact of humidity on the $\mathrm{LFL}_{0}$ has been investigated experimentally and theoretically. While the feasibility of measuring lean flammability limits with an opposed-flow burner was demonstrated in Phase I, the experimental work in Phase II has explicitly defined the accuracy with which these measurements can be made.

The numerical modeling of the chemical kinetics provides predictions which help explain the experimental results. Additionally, the numerical model allows one to vary the initial temperature, pressure, relative humidity and fuel/air composition to investigate the qualitative impact of these variables and compare combustion characteristics of combinations which are beyond the testable range of the experimental facility.

The major findings from Phase II of this project are the following:

- Extrapolating experimental extinction measurements to a zero-strain condition using the improved opposed-flow burner has yielded lean flammability limits to an accuracy of three significant digits for R-32 in air mixtures.

- The lean flammability limit of unstrained R-32/air mixtures is $14.0 \% \pm 0.8 \%$ by volume under ambient temperature and pressure conditions.

- At a relative humidity of $43 \%$, the addition of water vapor to air does not impact the flammability limit of R-32 beyond the uncertainty of the measurement.

- Premixed R-134a/air flames cannot be established on the opposed-flow burner operating at ambient temperature and pressure.

Table IX: $\quad$ Summary of $\mathrm{CH}_{4}$ and R-32 test results and conditions for Phase II

\begin{tabular}{c|c|c|c}
\hline Fuel and Oxidizer & $\begin{array}{c}\text { LFL }_{\mathrm{o}} \pm 95 \% \\
\text { Confidence Interval } \\
\text { (\% volume in air })\end{array}$ & $\begin{array}{c}\text { Laboratory barometric } \\
\text { pressure range } \\
(\mathrm{kPa})\end{array}$ & $\begin{array}{c}\text { Laboratory } \\
\text { temperature range } \\
\left({ }^{\circ} \mathrm{C}\right)\end{array}$ \\
\hline $\begin{array}{c}\mathrm{CH}_{4} \text { in Dry Air } \\
\text { R-32 in Dry Air } \\
\begin{array}{c}\text { R-32 in Air } \\
\text { with 43 \% R.H. }\end{array}\end{array}$ & $14.0 \pm 0.1$ & $98.8 \pm 0.2$ & $26.6 \pm 0.1$ \\
\hline
\end{tabular}


- The extension of the methane mechanism of the chemical kinetics code CHEMKIN to include $\mathrm{R}-32\left(\mathrm{CH}_{2} \mathrm{~F}_{2}\right)$ and $\mathrm{R}-125\left(\mathrm{C}_{2} \mathrm{HF}_{5}\right)$ yields predictions that are useful in understanding the differences between the methane and $\mathrm{R}-32$ results.

- CHEMKIN results predict that humidity can either increase or decrease the lean flammability limit of a mixture, depending on the chemical composition of the refrigerant.

- Extrapolation of the calculated flame speed-to-thickness ratio to zero suggests a computational technique to evaluate the lean flammability limit of methane/air mixtures. At this time, the extension of this technique to other fuels yields conflicting results.

Future directions: The establishment of a reliable approach to determine lean flammability limits suggests a number of opportunities. More fuels, refrigerants and combinations, will be tested to provide a broader understanding of the capabilities of the burner and the applicability of $\mathrm{LFL}_{0}$ to the lean flammability limit of other fuels. Local velocity measurements will provide a quantitative understanding of the generality of the global strain rate currently used to find $\mathrm{LFL}_{\mathrm{O}}$. Increased calibration precision will further minimize uncertainty in the $\mathrm{LFL}_{\mathrm{o}}$.

Results from additional single and double carbon fuels will allow comparison to CHEMKIN calculations and increase our confidence in the HFC/air chemical kinetics mechanism. Expanding the calculations to encompass the opposed-flow dynamics of the experimental tests, with the buoyant forces and heat loss incorporated, would allow direct comparison between the theoretical results and the experimental results.

The concept of using relative rankings for weakly flammable refrigerants, pure and in combinations, needs to be explored, possibly with the reduction in flame velocity or the sensitivity to an oxygen enriched environment as additional evaluation parameters.

\section{Acknowledgments}

The authors would like to thank Drs. Jim Filliben and Keith Eberhart of the NIST Statistical Engineering Division for consultation on the uncertainty analysis and Mr. William Rinkinen, Mr. Jaeson Howze, and Ms. Michelle King for their varied and numerous contributions. 


\section{Appendix}

Uncertainty analysis: In the plots of the extinction equivalence ratio, $\Phi_{\mathrm{x}}$, versus the global strain rate, $K$, a linear fit as plotted gives an equation of the form:

$$
\Phi_{x}=\Phi_{o}+m K
$$

where $m$ is slope of the line, and $\Phi_{0}$ is the intercept at the point of zero strain. A typical way of solving for the values of $m$ and $\Phi_{0}$ is to perform a least squares linear fit of the data, where a function of the residual standard deviation, the standard error about the intercept, predicts the uncertainty in $\Phi_{o}$. However, the calculation of a least squares linear fit and the associated residual standard deviation assume that $\Phi_{\mathrm{x}}$ and $K$ are independent variables. In our case this is not so, since both $\Phi_{\mathrm{X}}$ and $K$ are functions of the molar flow of air and fuel: $\Phi_{\mathrm{X}}=k_{\mathrm{l}}\left(\dot{\mathrm{X}}_{f} / \dot{\mathrm{X}}_{a}\right)$ and $K=k_{2}\left(\dot{\mathrm{X}}_{f}+\dot{\mathrm{X}}_{a}\right)$. The above equation now written as a function of $\dot{\mathrm{X}}_{f}$ and $\dot{\mathrm{X}}_{a}$ is

$$
k_{1}\left(\frac{\dot{\mathrm{X}}_{f}}{\dot{\mathrm{X}}_{a}}\right)=\Phi_{o}+m \cdot\left[k_{2}\left(\dot{\mathrm{X}}_{f}+\dot{\mathrm{X}}_{a}\right)\right]
$$

where the constants, $\mathrm{k}_{1}$ and $\mathrm{k}_{2}$, are the fuel equivalence constant and a value relating to the burner geometry, respectively. To solve for $m$ and $\Phi_{0}$ this equation needs to be written in the form of $\dot{\mathrm{X}}_{a}=\mathrm{f}\left(\dot{\mathrm{X}}_{f}\right)$ or $\dot{\mathrm{X}}_{f}=\mathrm{g}\left(\dot{\mathrm{X}}_{a}\right)$. Since the magnitude of the uncertainty in $\dot{\mathrm{X}}_{f}$ and $\dot{\mathrm{X}}_{a}$ is a function of their own magnitude (i.e. a percentage of the flow), we select the independent variable with the smaller uncertainty for the $\mathrm{X}$-axis. Consequently, we rewrite the above equation as $\dot{\mathrm{X}}_{a}=\mathrm{f}\left(\dot{\mathrm{X}}_{f}\right)$. Using the standard quadratic solution, we get:

$$
X_{a}=\frac{-\left(\Phi_{o}+m \cdot k_{2} \dot{\mathrm{X}}_{f}\right) \pm \sqrt{\left(\Phi_{o}+m \cdot k_{2} \dot{\mathrm{X}}_{f}\right)^{2}+4 m k_{2} \cdot\left(k_{1} \dot{\mathrm{X}}_{f}\right)}}{2 m k_{2}}
$$

Since the lean limit and all of the variables and constants are positive, and the discriminant is the larger term of the numerator, only the positive form will provide a viable value. Using a statistical analysis program, Dataplot, (Filliben and Heckert, 1992) it is possible to solve for $m$ and $\Phi_{\mathrm{o}}$. For these particular data sets the difference between the outcome of two types of fits is not large, however this might not always be the case. 


\section{References}

ASTM E 681-1994, "Standard Test Method for Concentration Limits of Flammability of Chemicals"; American Society for Testing and Materials, Philadelphia, PA.

Barnard, J.A., Bradley, J.N. Flame and Combustion, Second Edition, Chapman and Hall, N.Y., Chapter 3: "Flames and combustion waves" 1985.

Burgess, D.R.F., Jr., Zachariah, M.R., Tsang, W., Westmoreland, P.R. Thermochemical and Chemical Kinetic Data for Fluorinated Hydrocarbons, NIST Technical Note 1412, National Institute of Standards and Technology, Gaithersburg, MD, July 1995.

Dekleva, T.W., Lindley A.A., Powell, P. "Flammability and Reactivity of Select HFCs and Mixtures"; ASHRAE Journal, December 1993, Atlanta, GA, 1993.

Filliben, J.J., Heckert, A. Dataplot: Interactive Graphics and Data Analysis Language; Computing and Applied Mathematics Laboratory, NIST, August 1992.

Glassman, I. Combustion, Academic Presss, Inc., N.Y., Chapter 4, Section A, "Laminar Flame Speed," 1977.

Gordon, S., McBride, B. Computer Program for Calculation of Complex Chemical Equilibrium Compositions and Application; NASA Reference Publication 1311, NASA Scientific and Technical Information Program, October 1994.

Greenspan, L. "Humidity Fixed Points of Binary Saturated Aqueuous Solutions"; Journal of Research of the National Bureau of Standards - A. Physics and Chemistry, Vol. 81A, No. 1, Jan. - Feb. 1977.

Grob, D. "Flammability Characteristics of R-32 and R-32 Mixtures"; Proceedings of the Symposium to Evaluate R-32 and R-32 Mixtures in Refrigeration Applications: Environmental Protection Agency, Washington, D.C., March 19-20, 1991.

Grosshandler, W. RADCAL: A Narrow-band Model for Radiation Calculations in a Combustion Environment, NIST Technical Note 1402, National Institute of Standards and Technology, Gaithersburg, MD, April 1993.

Hertzberg, M. "The Theory of Flammability Limits: Natural Convection," Bureau of Mines Report of Investigation, RI-8127, 1976.

Hertzberg, M. "The Theory of Flammability Limits: Conductive-convective Wall Losses and Thermal Quenching," Bureau of Mines Report of Investigation, RI-8469, 1980.

Hertzberg, M. "The Theory of Flammability Limits: Radiative Losses and Selective Diffusional Demixing," Bureau of Mines Report of Investigation, RI-8607, 1982.

Hertzberg, M. "The Theory of Flammability Limits: Flow Gradient Effects and Flame Stretch," Bureau of Mines Report of Investigation, RI-8865, 1984.

Ishizuka, S., Law, C.K. "An Experimental Study on Extinction and Stability of Stretched Premixed Flames"; Nineteenth Symposium (International) on Combustion: The Combustion Institute, pp 327-335, 1982.

Kee, R.J., Grcar, J.F., Smooke, M.D., Miller, J.A. A Fortran Program for Modeling Steady OneDimensional Premixed Flames, Sandia Report SAND85-8240, 1985. 
Kee, R.J., Miller, J.A., Jefferson, T.H. CHEMKIN: A General Purpose Problem-independent, Transportable, Fortran Chemical Kinetic Program Package, Report number SAND80-8003, Sandia National Laboratories, Livermore, CA, 1980.

Landau, L.D., Lifshitz, E.M. Fluid Mechanics, Pergamon Press, 1986.

Law, C.K., Egolfopoulos, F.N. "A Kinetic Criterion of Flammability Limits: Lean Limits of $\mathrm{C}-\mathrm{H}-\mathrm{O}-\mathrm{N}-\mathrm{Br}$ Systems"; Proceedings of the Chemical and Physical Processes in Combustion: Fall Technical Meeting, Clearwater Beach, FL, December 5-7, 1988.

Law, C.K., Zhu, D.L., Yu, G. "Propagation and Extinction of Stretched Premixed Flames"; Twenty-first Symposium (International) on Combustion: The Combustion Institute, pp 1419-1426, 1986.

Linteris, G.T., Truett, L. "Inhibition of Premixed Methane-air Flames by Fluoromethanes," Combustion and Flame, in press, 1996.

Miller, J.A., Bowman, C.T. "Mechanism and Modeling of Nitrogen Chemistry in Combustion," Prog. Energy Comb. Sci. 15, 287, 1989.

Morel, T. "Comprehensive Design of Axisymmetric Wind Tunnel Contractions"; Journal of Fluids Engineering, June 1975, pp 225-233, 1975.

Ohnishi, H. "Relationship Between Flammability and Composition Ratio of HFC-32/HFC-134a Blend"; Proceedings of the ASHRAE/NIST Refrigerants Conference: R-22/R-502 Alternatives, Gaithersburg, MD, August 19-20, 1993.

Pitts, W.M., Mulholland, G.W., Breuel, B.D., Johnsson, E.L., Chung, S., Harris, R.H. "Realtime Suppressant Concentration Measurements"; in Fire Suppression System Performance of Alternative Agents in Aircraft Engine and Dry Bay Laboratory Simulations; Gann, R.G., Ed.; NIST SP 890 :Vol. II, 348, November, 1995.

Richard, R.G., Shankland, I.R. "Flammability of Alternative Refrigerants"; ASHRAE Journal, Atlanta, GA, April 1992.

Sorenson, S.C., Savage, L.D., Strelow, R.A. "Flammability Limits - A New Technique"; Combustion and Flame, 24, pp 347-355, 1975.

Tanoff, M.A., Dobbins, R.R., Smooke, M.D., Burgess, D.R., Zachariah, M.R., Tsang, W., Westmoreland, P.R. " $\mathrm{C}_{1}$ and $\mathrm{C}_{2}$ Fluoro- and Hydrofluorocarbon Effects on the Extinction Characteristics of Methane vs. Air Counterflow Diffusion Flames"; accepted for presentation at the Twenty-Sixth International Symposium on Combustion, Naples, Italy, July 28 - August 2, 1996.

Tison, S., "A Critical Evaluation of Thermal Mass Flow Meters," Journal of Vacuum Science and Technology A, to be published July 1996.

Womeldorf, C., King, M., Grosshandler, W. "Lean Flammability Limit as a Fundamental Refrigerant Property," Interim Technical Report, DOE/CE/23810-58, The Airconditioning and Refrigeration Technology Institute, ARTI MCLR Project Number DE-FG02-91CE23810, March 31, 1995.

Yamaoka, I., Tsuji, H. "An Experimental Study of Flammability Limits Using Counterflow Flames"; Seventeenth Symposium (International) on Combustion: The Combustion Institute, pp 843-854, 1979.

Zabetakis, M.G. Flammability Characteristics of Combustible Gases and Vapors; Bulletin 627, Bureau of Mines, National Technical Information Service, Springfield, VA, 1965. 